\title{
رحلة البطل في ثلاث ملاحم قديمة
}

\section{Hero's journey in three ancient sagas}

\section{sleel}

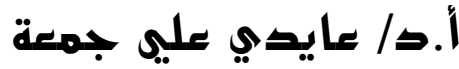

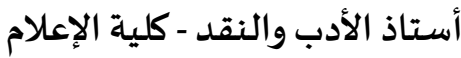

$$
\text { جامعة أكتوبر للعلوم الحديثة والآداب- مصرب }
$$

\section{Doi: 10.12816/mdad.2021.152300}

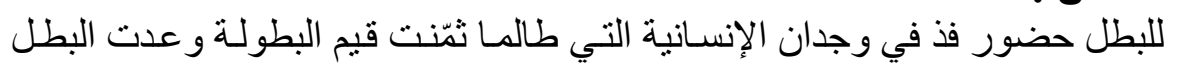

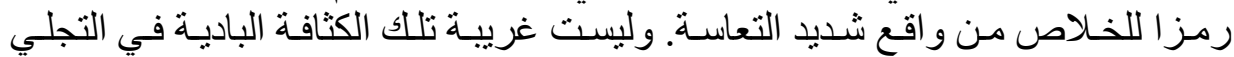

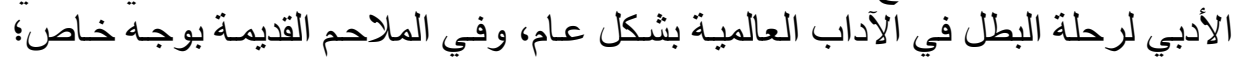

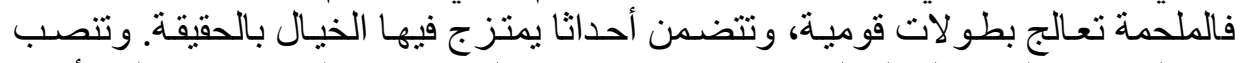

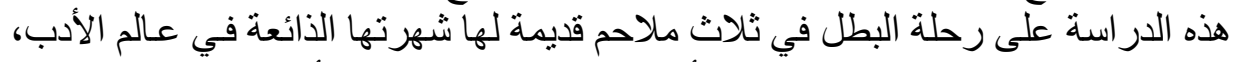

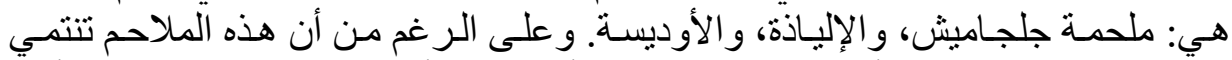

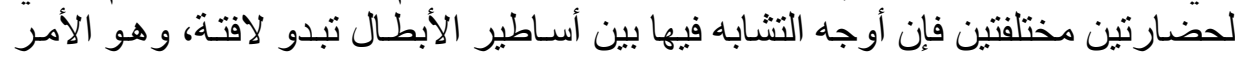

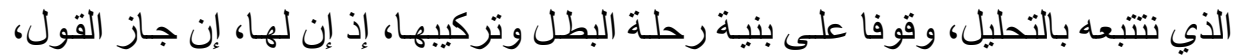

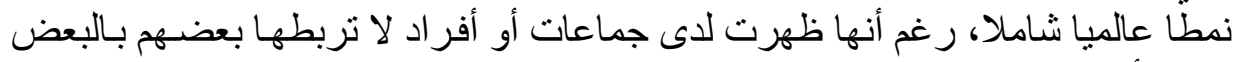
الآخر أية علاقات ثقافية مباثرة أناتهات

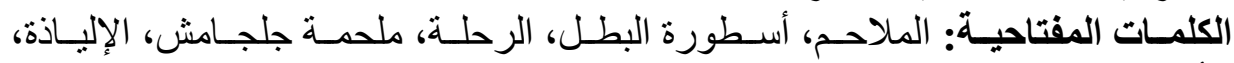

\section{Abstract:}

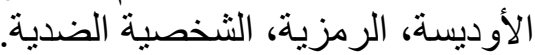

The hero has a unique presence in the consciousness of humanity, which has always valued the values of heroism and promised the hero a symbol of salvation from a very unhappy reality. It is not strange that the intensity shown in the literary manifestation of the hero's journey in world literature in general, and in ancient epics in particular; The epic deals with national 
heroics, and includes events in which fiction and reality are mixed. This study focuses on the hero's journey in three ancient epics that are famous in the literary world, namely: Gilgamesh, The Iliad, and The Odyssey. Although these epics belong to two different civilizations, the similarities in them between the myths of the heroes seem remarkable, and this is what we follow through analysis, standing on the structure and composition of the hero's journey, as they have, so to say, a comprehensive global pattern, although they appeared in groups or Individuals who do not have any direct cultural relations with others.

Keywords: epics, myth of the hero, the journey, the epic of Gilgamesh, the Iliad, the Odyssey, symbolism, the antipersonal character.

تعد الرحلة من الرموز الأولية في اللاوعي الجماعي، ومنذ الملاحم القديمة وجدنا

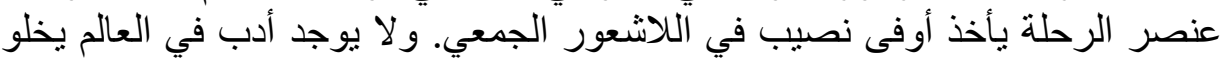

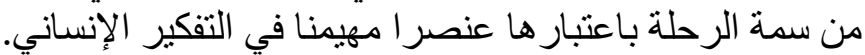

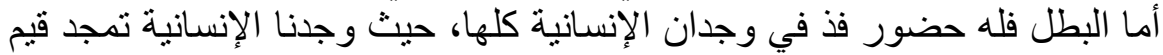

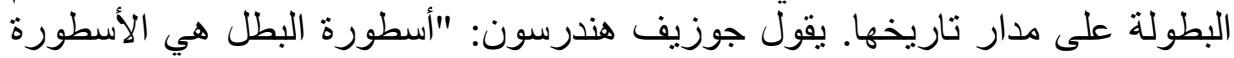

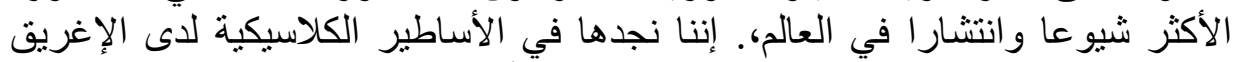

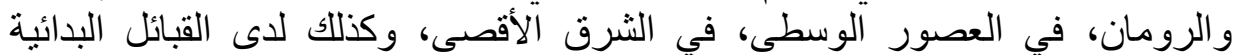

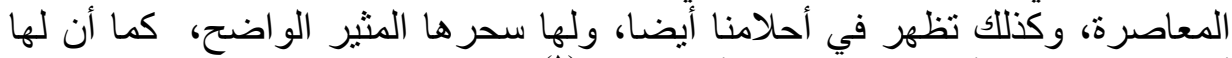

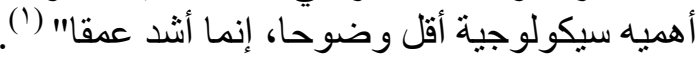

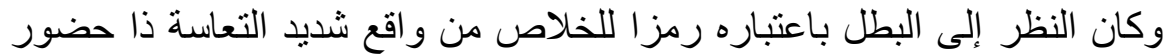

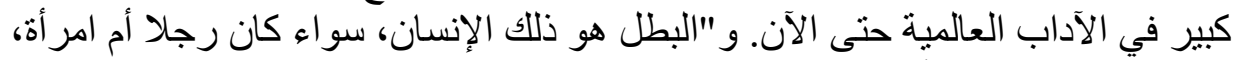

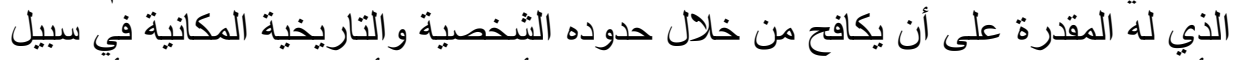

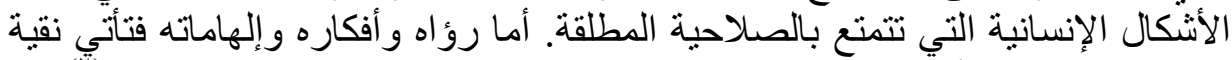

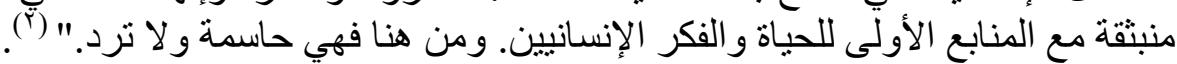

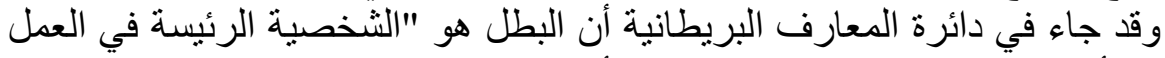

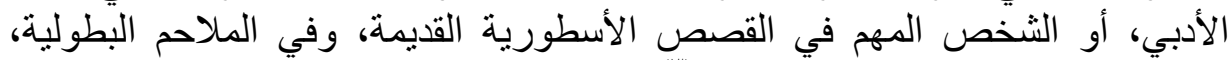

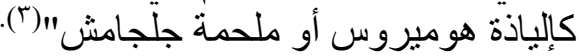
و علماء الاجتماع "لاينظرون إلى الأسطورة من خلادل الفرد، بل من خلال علاقتها 
بالطقوس التي تقوم بدور الجهاز العصبي في حياة الجماعة، ووصلو ا بعد درس وتحليل

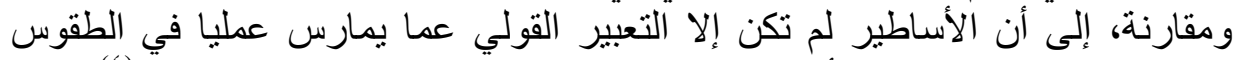

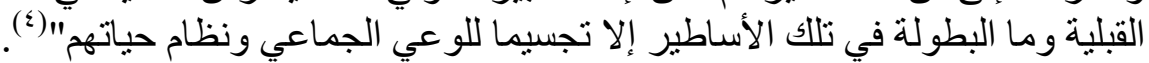

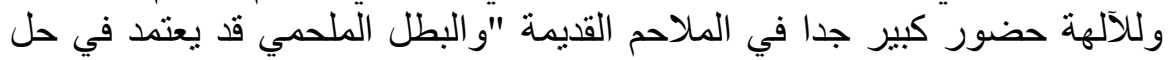

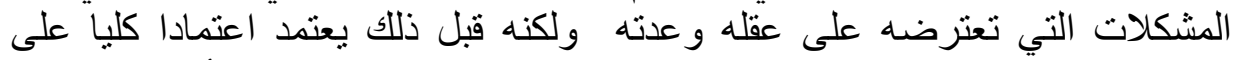

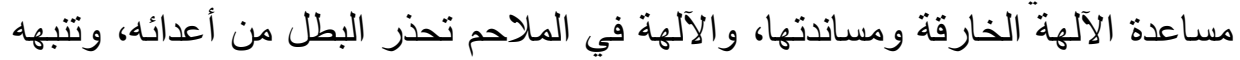

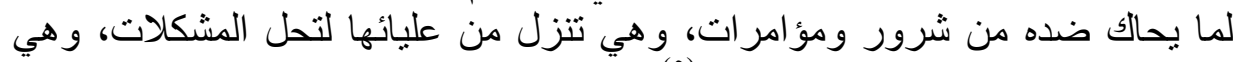

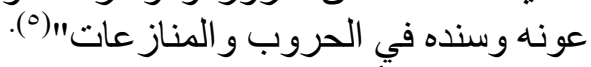

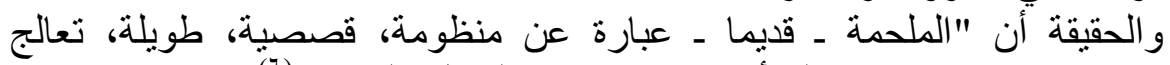

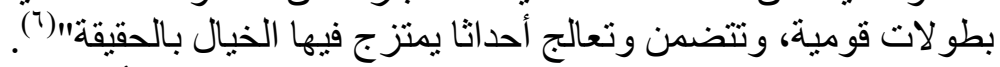

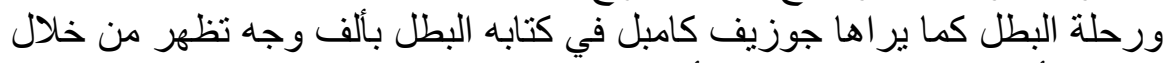

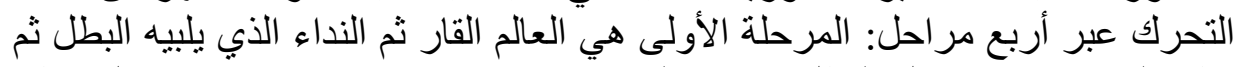

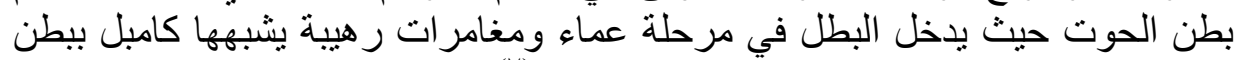

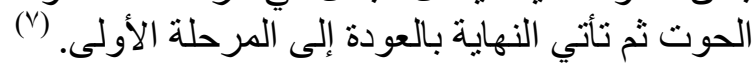

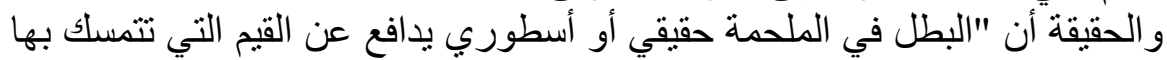

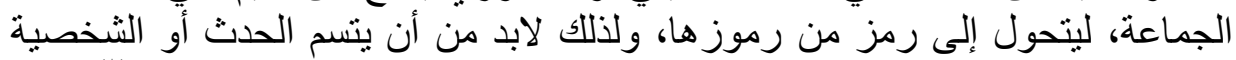

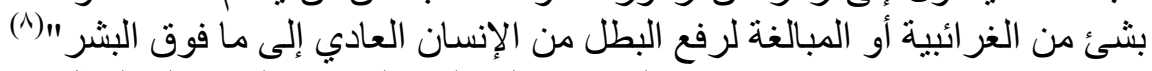

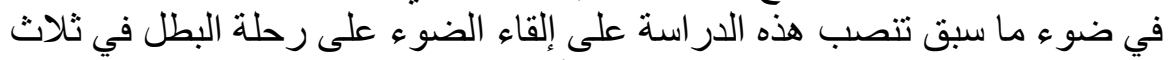

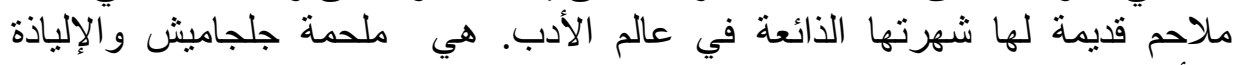
وملحمة جلجامش ملحمة بابلية وسومرية قديمة تنتمي لأرض بلانداد الرافينين،

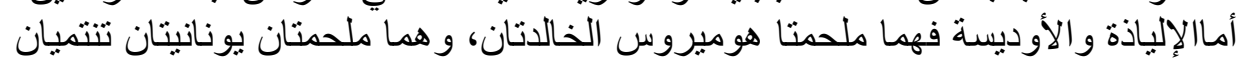

و ولى ألر غم من أن هذه الملاحم تتنمي لحضارتين مختلفتين فإن أوجه التثابه بينها

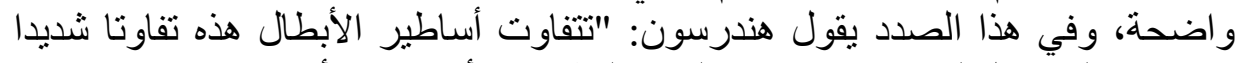

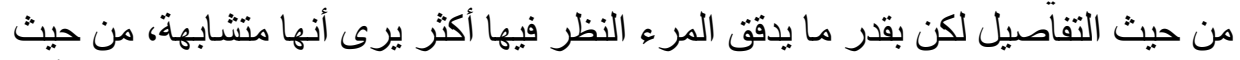

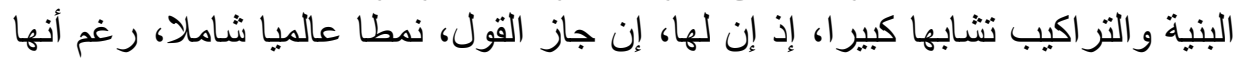

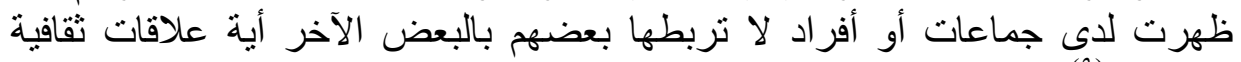

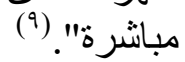
رحلة البطل في ملحمة جلجاميش:

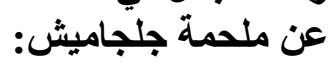
تعد ملحمة جلجاميش قمة أدبية شاهقة في تاريخ بلاد الر افدين. وهي من أغوى 
ملاحم العالم القديم، ومنذ اكتشاف نصها حو الي منتصف القرن التاسع عشر وغو ايتها لا

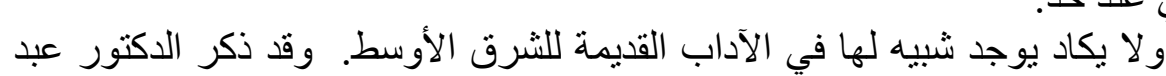

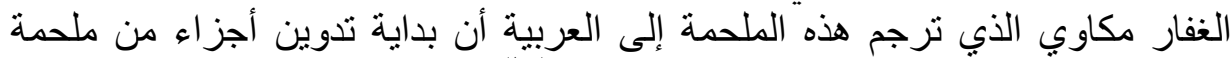

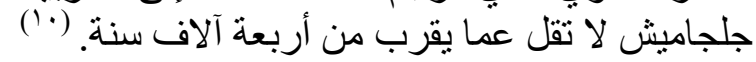
وبذا فإنها تعد الأقدم بين الملاحم المعروفة الافة فئة

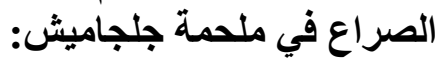

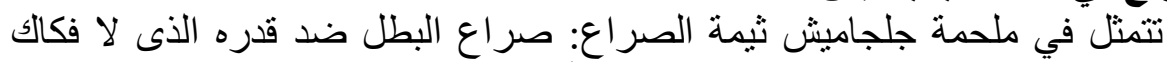

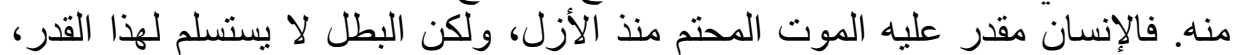
و إنما يقوم برحلة فائقة من أجل التغلغ التبل عليه. سمات البطل:

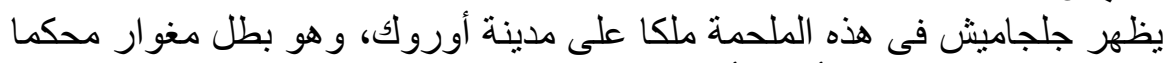

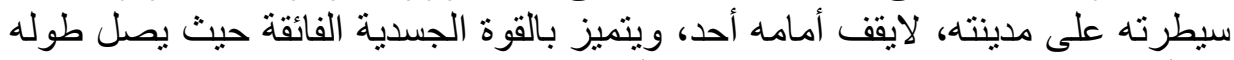

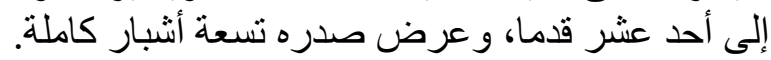
" لما خلق جلجاميش، أكمل بطل الآلهة هيئته. اشترك الآلهة فى صنع الأهة هينه صورته:

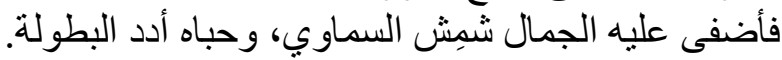

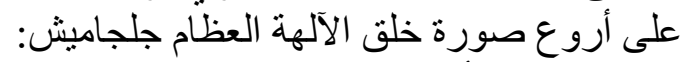

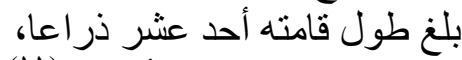
و وعرض صندره تسعة أشبار "(1)

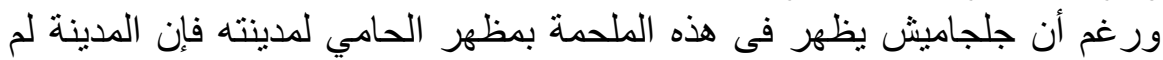

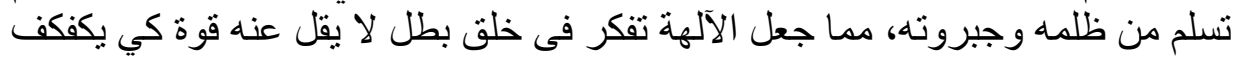
من غربه.

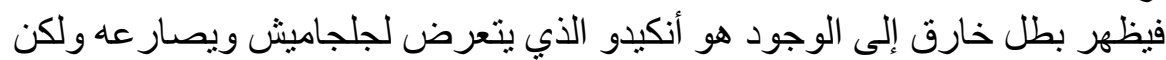

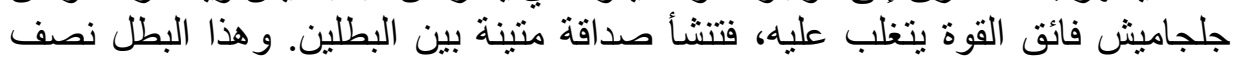

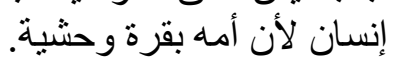

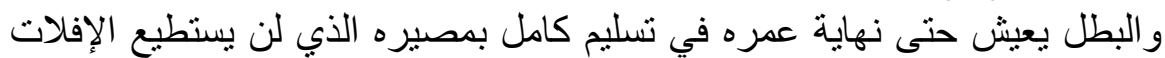

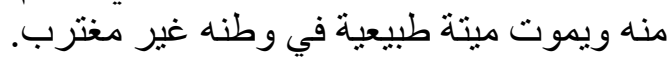

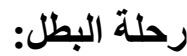

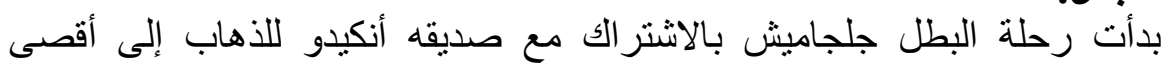

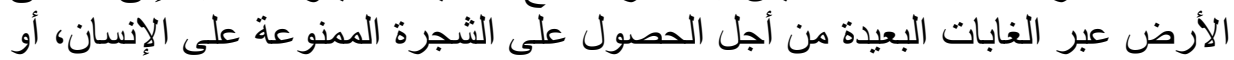




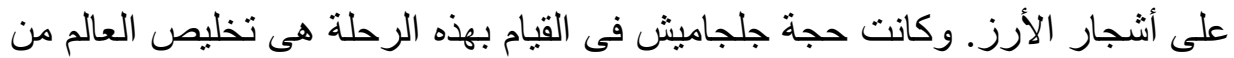

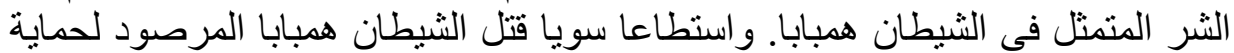

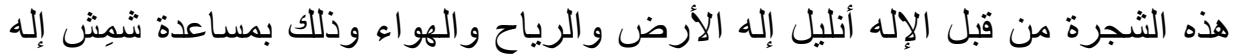

و أثناء عودتهما اشتهت عثتار إلهة الحب جلجاميش، ولكنه صدها لمعرفته بالغدر

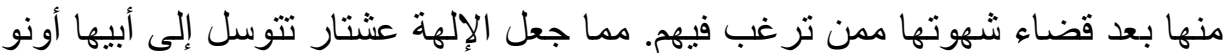

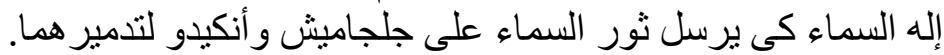

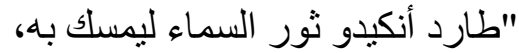
ثم أطبق على ذيله، وقبض عليه بكلتا يديه،

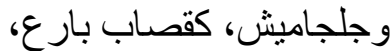

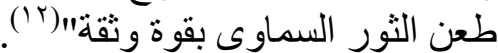

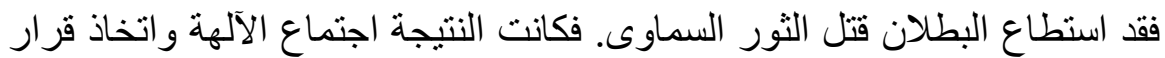

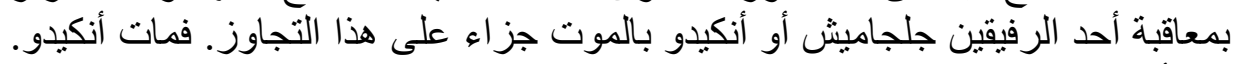

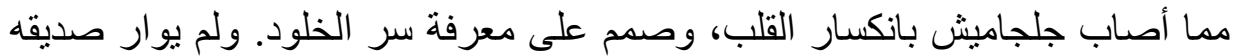

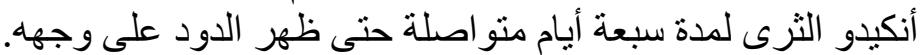
"بكى جلجاميش صديقه أنكيدو بكاء مراء أبراء و هام (على وجهه) في البراري: "ألن يكون مصيرى، وجهة في إذا مت، مثل مصير أنكيدو؟

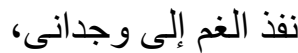

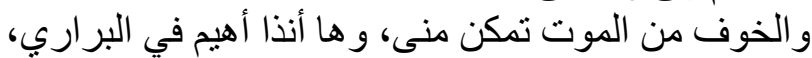

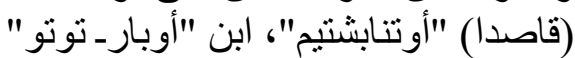

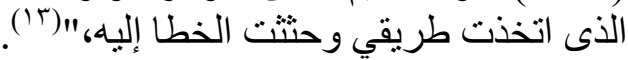

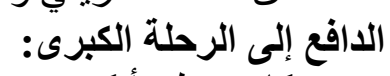

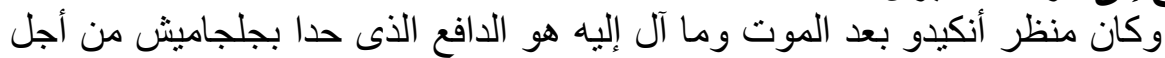

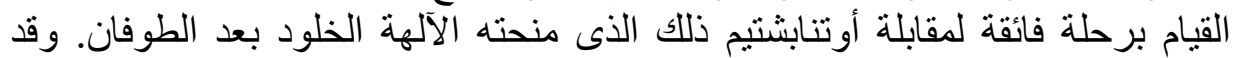

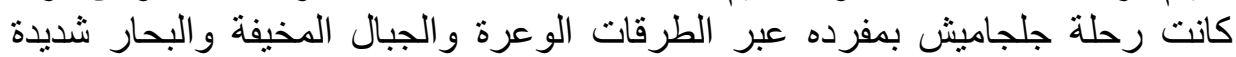

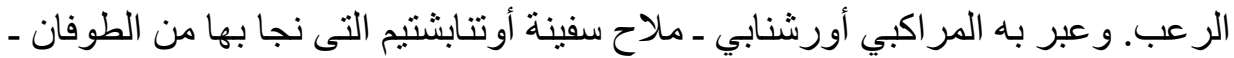

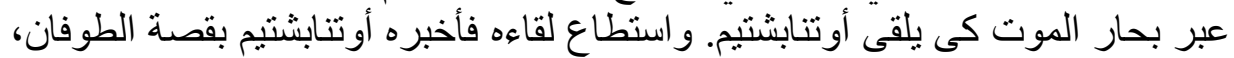

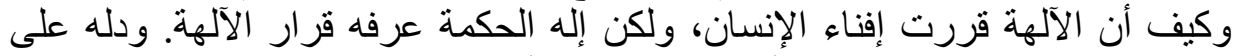

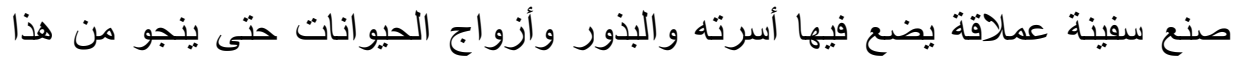
الطوفان المهلك. 
ومن هنا فإن الدافع لرحلة جلجاميش الفائقة هو معرفة سر الخلود، حتى يعيد صديقه

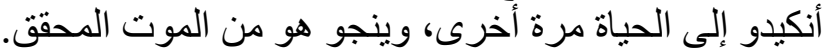

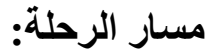

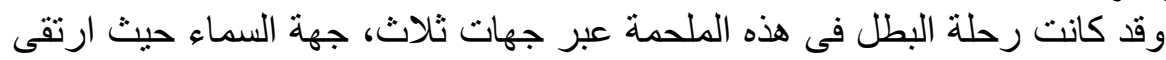

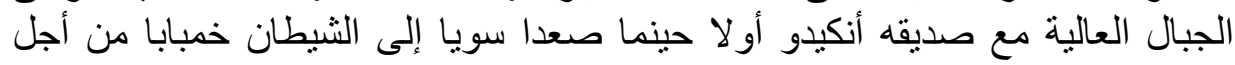

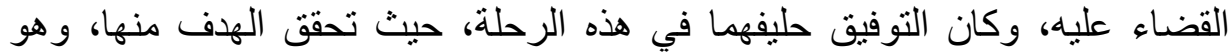

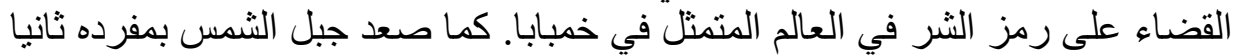

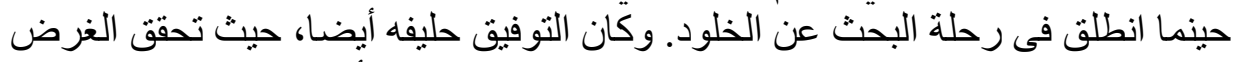

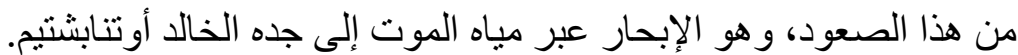

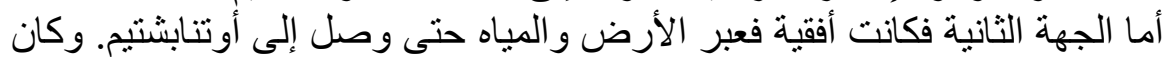

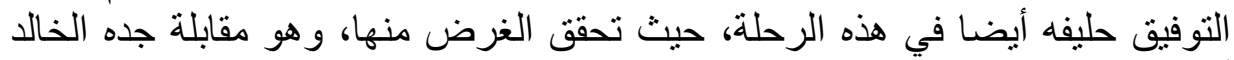
أوتنابشتيم.

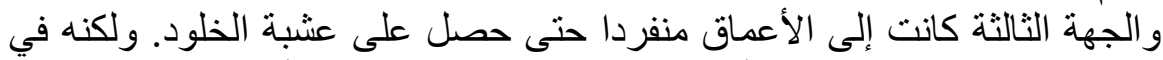

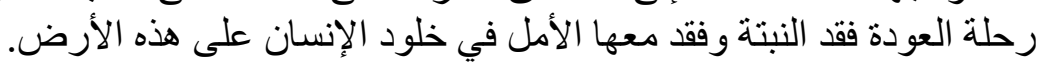

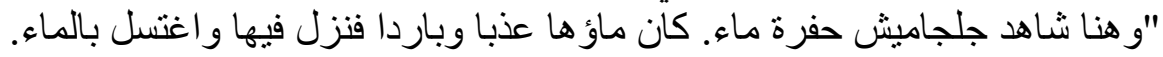

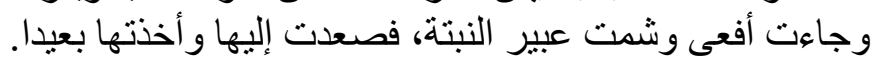

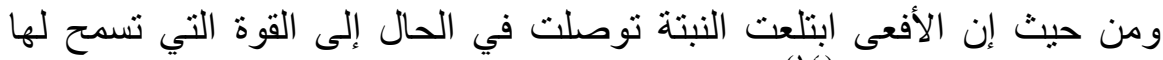

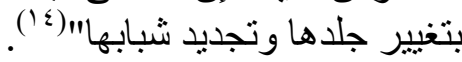

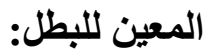
أما عن دور المعين فى الرحلة فى هذه الملحمة فيظهر من خلال الآلهة التي تحب

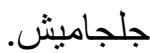

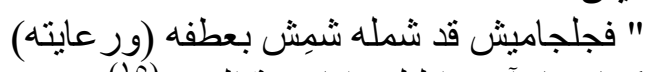

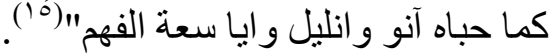

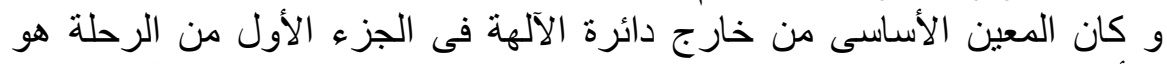

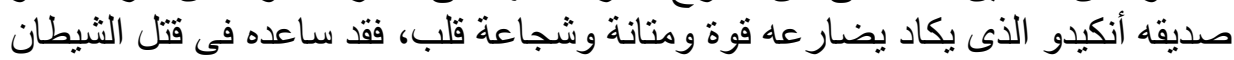

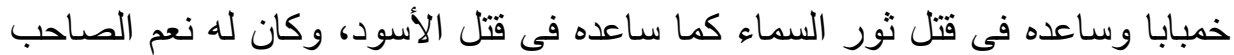

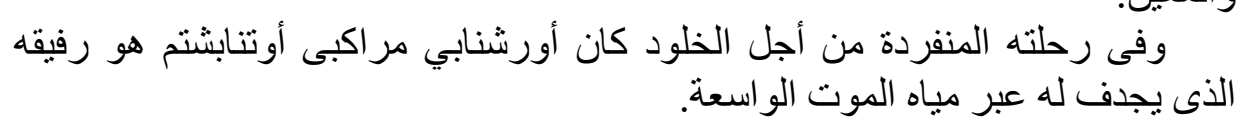
و المعين.

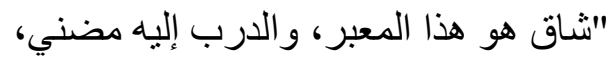

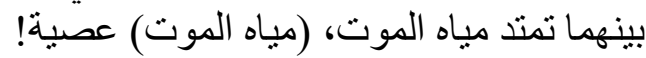

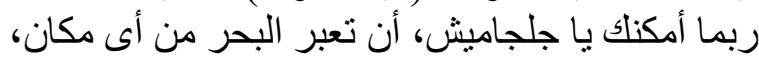




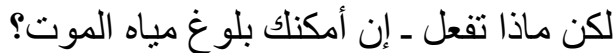

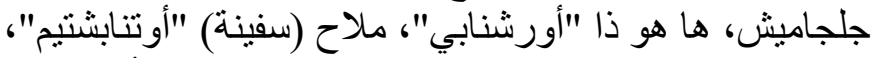

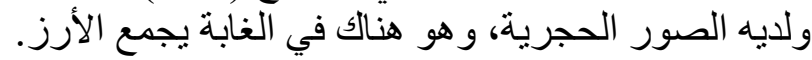

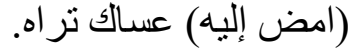

$$
\begin{aligned}
& \text { إذا استطعت فاعبر معه (البحر) }
\end{aligned}
$$

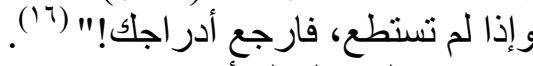

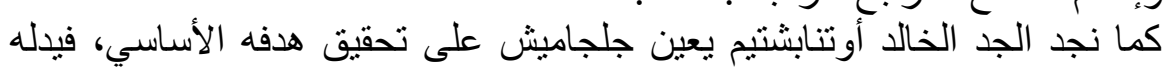

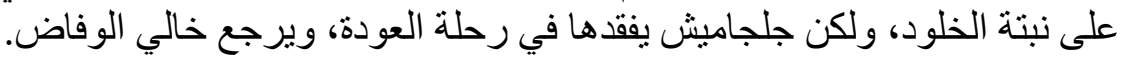
المضاد للبطل:

يظهر المضاد للبطل في ملحمة جلجاميش عبر دوائر مختلفة، فهناك دائرة الآلهة

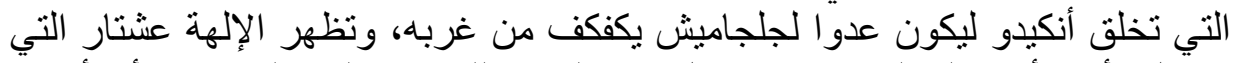

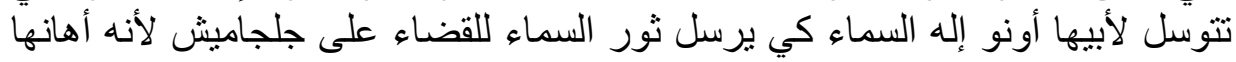
برفضه لطلبها فى الاستمتاع بـاء.

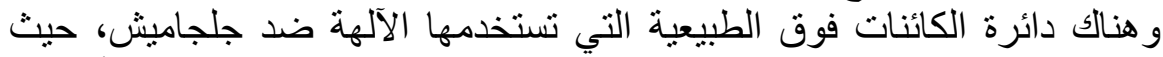

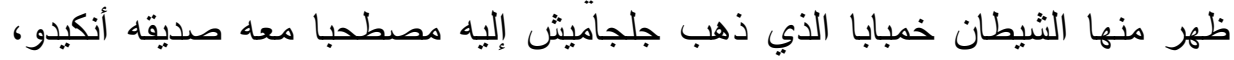
و استطاع جلجاميش القضاء عليه.

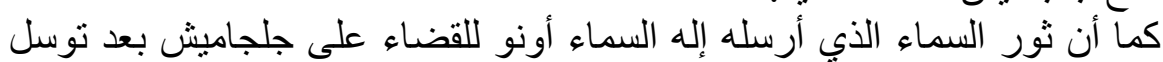

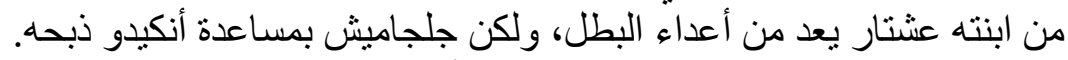

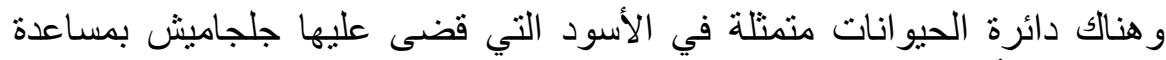

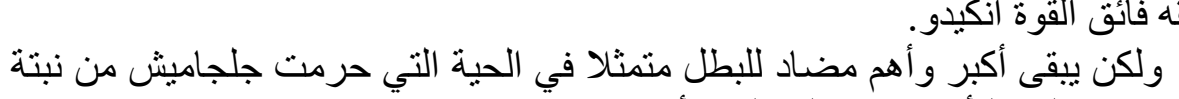
الخلود، وجعلت اليأس يسكن قلبه والبه إلى الأبد. النبل في رحلة جلجاميش:

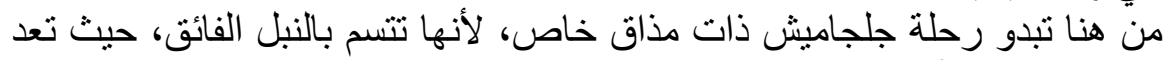

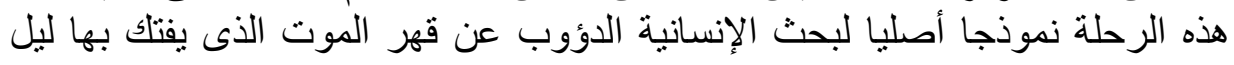
ومن ملامح نبل هذه الرحلة أن المحرك الأول فيها هو الصديق. وبذا تعلى قيمة نهار.

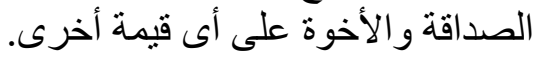

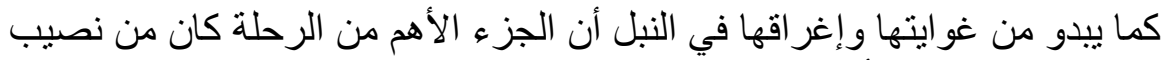

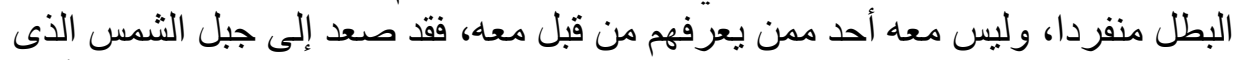

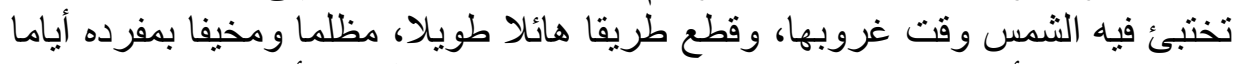

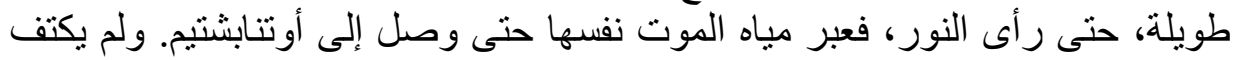


بذلك بل إنه نزل إلى أعماق المياه منفردا وحصل على نبتة الخلود، ولكن الفثل كان نصيبه فى النهاية. لقد بدت جسارة جلجاميش فائقة، وقلبه لا يعرف التردد أو الو هائه الون في سبيل تحقيق هدفه. و إذا كان الفشل حليفه فى النهاية فإنه فنشل نبيل. لإنه

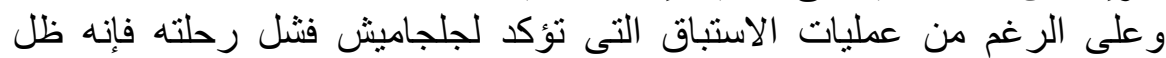
مصمما عليها، و هو في حالة من النبل الفريد. " تكدر شمِش وذهب وهي (بنفسـ) إليه النيه

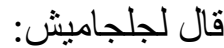

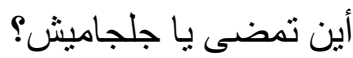

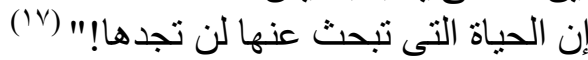

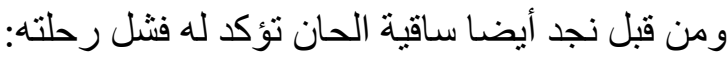

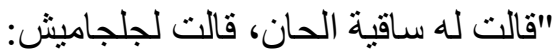

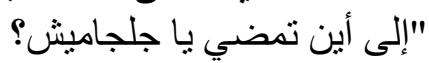

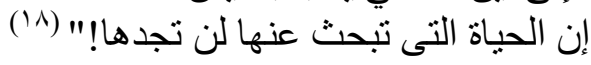

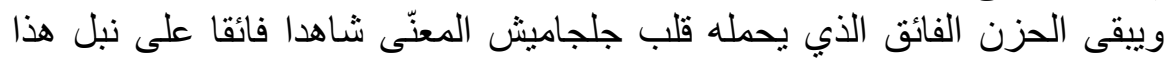

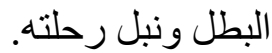
نجاح الرحلة أو فشلها:

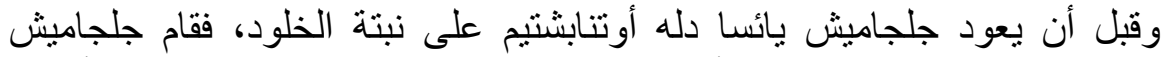

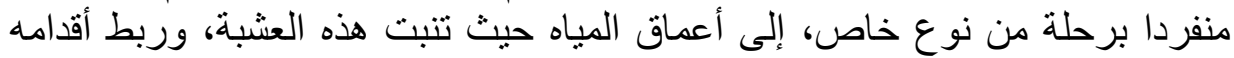

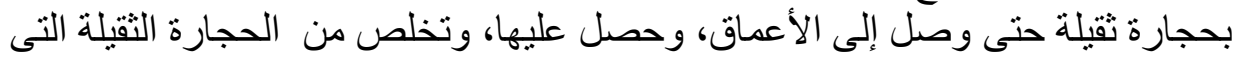

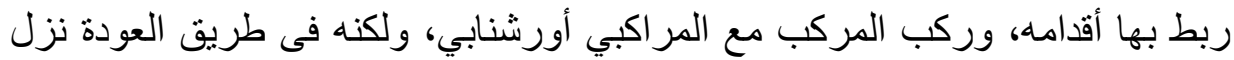

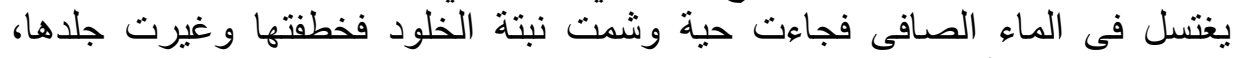

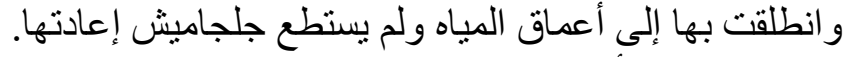

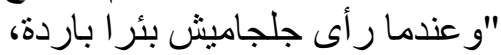
نزل فيها ليغتسل (بالماء) شمت أفعى شذا النبتة.

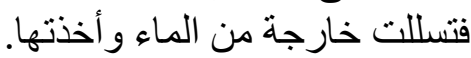
و وند عودتها غيرت جلد هنا.

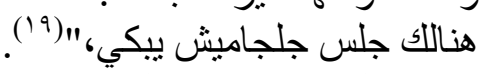

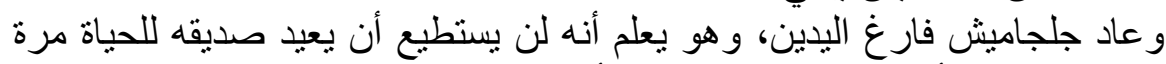
أخرى، ولن يستطيع أن يعيش هو نفسه إلى الى الأبد، ولكن الجنس لن البشري سيظل أنسئ من بعده. 
رمزية الرحلة في ملحمة جلجاميش:

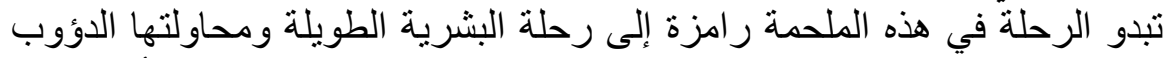

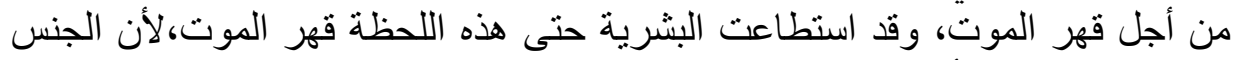
البشري على هذه الأرض لم لم يفن بعد.

فالكوت انتصر على الإنسان على المستوى الفردي، فلم نجد إنسانا خالدا، أو قاهرا

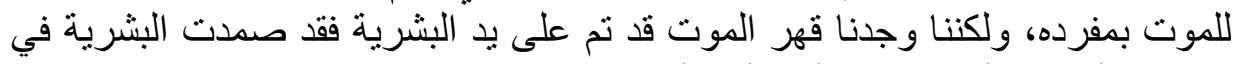
مواجهة الموت على مدار رحلتها الطويلة.

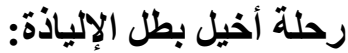

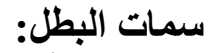
يظهر أخيل بطل الإلياذة باعتباره أقوى الدحاربين على الإطلاق في حرب طرو ادة.

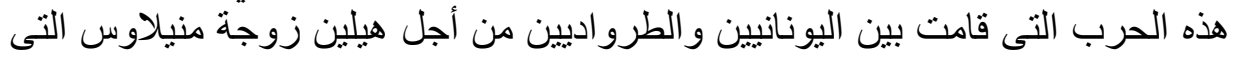

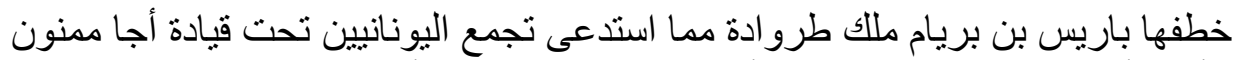

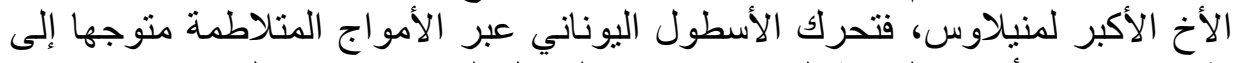

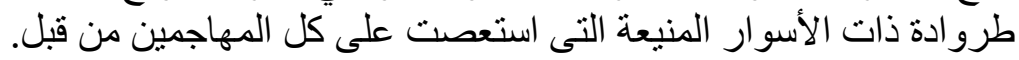

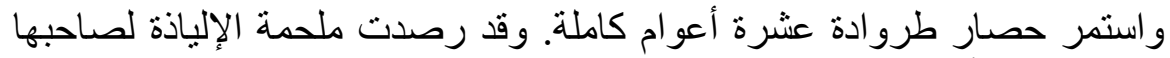

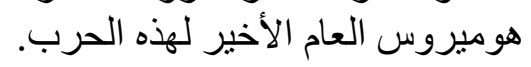
فىى البداية تظهر كفة اليونانيين على أعدائهم بفضل وجود أخيل السريع القدمين على حد وصف الإلياذة له.

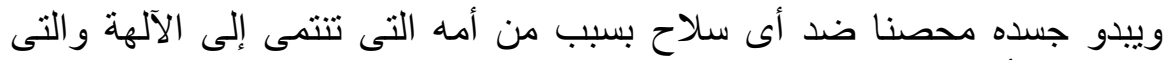

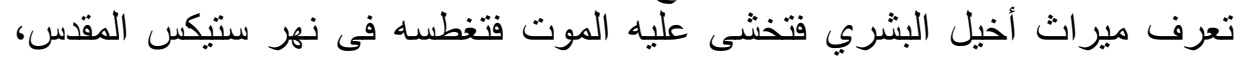

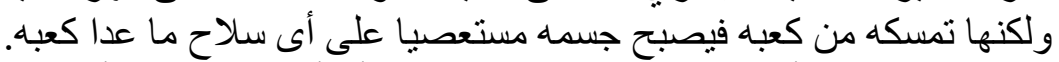

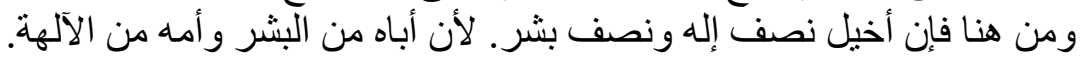

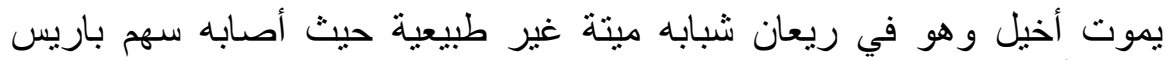

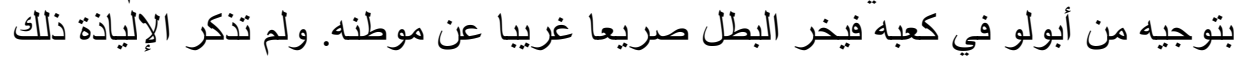
لأنها انتهات عند جنازة هيكتور الذي قتلكه آخيل.

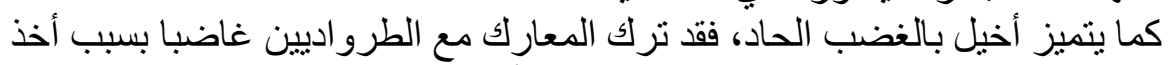

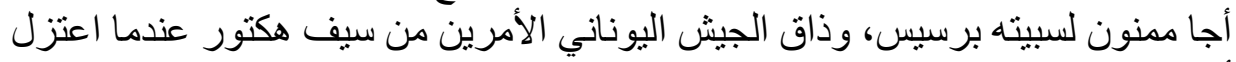

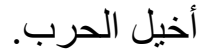
كما ظهر غضبه الحاد بصورة مر عبة حينما قتل هكتور صديقه باتروكلوس، وعاد الطباد

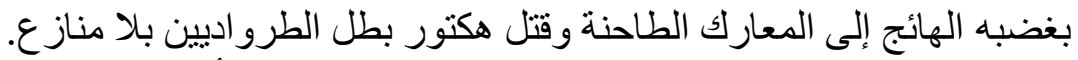

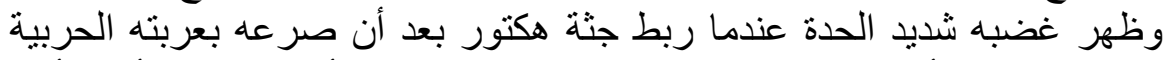
وظل يدور بها حول أسوار طروادة بلا رحمة اثنى عشر يوما، أمام زوجته و أبيه وأهل 
طروادة وجيشها.

و ون هنا فإن سمة الوحشية لا تبدو بعيدة عن هذا البطل الثهير. كما يبدو من سماته شدة الميل إلى النساء، فئل فيدة ظهر ميله الثديد إلى أسيرته الطرو ادية برسيس.

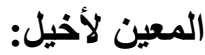

أخيل يقاتل على رأس جيش اليونانيين ومن هنا فإن الجيش اليوناني كله يعد فى دور

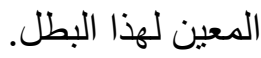

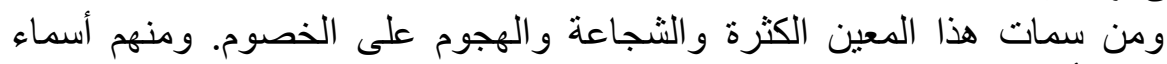

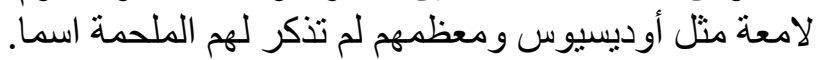

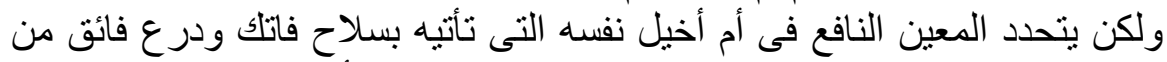

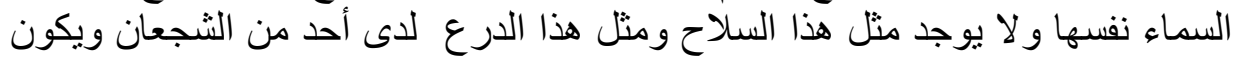

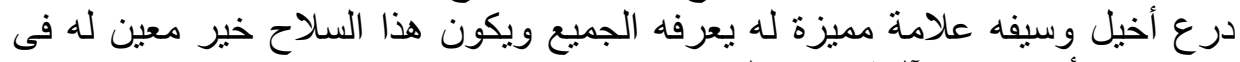

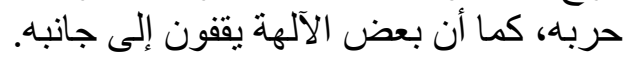

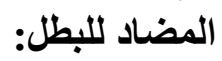

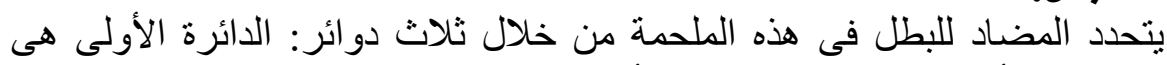

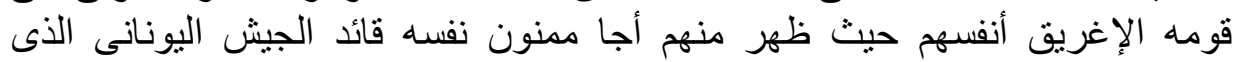

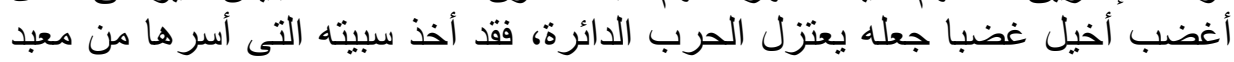

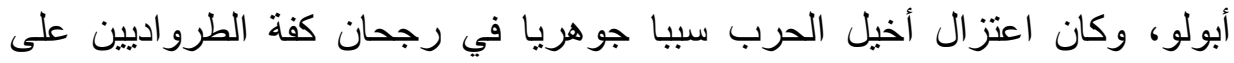

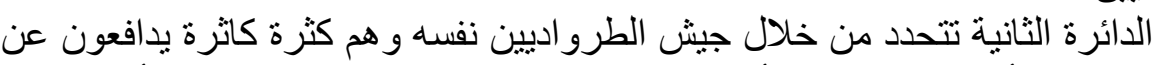

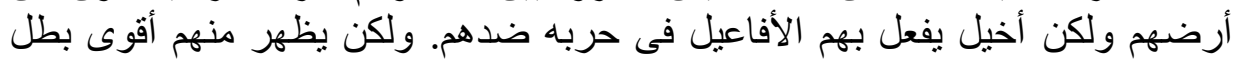

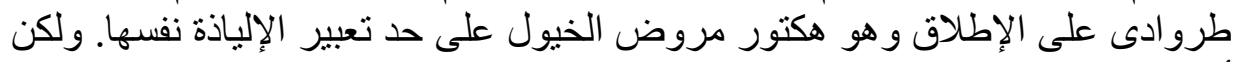

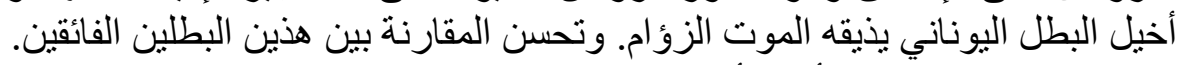

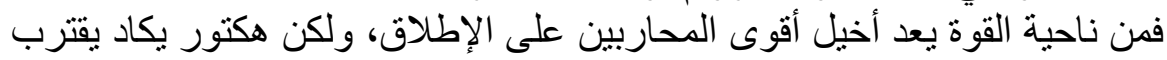

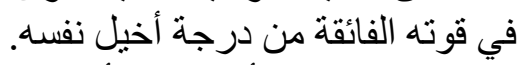
ومن ناحية الأصل فإن أخيل نصف إلفيله إله، أما هكتور فهو إنسان لأن أباه بشر وأمه من البشر أيضا. ومن ناحية المستوى الاجتماعي فإن أخيل بن بيلوس ملك المرميديين و أمه من

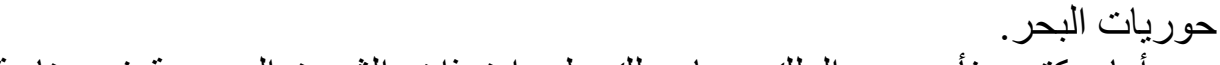
أما هكتور فأبوه هو الملك بريام ملك طروادة ذات الثهرة العريضة في مناعة أسوار ها. ومن ناحية المرحلة العمرية فقد كان الاثنان في شرخ الثباب. ومن ناحية المهارة 
القتالية فقد كان أخيل ماهر ا مهارة لا تضارع في حين كان هكتور ماهر ا أيضا مهارة لاتضار ع. ومن ناحية مهار ات القيادة فقد كان أخيل قائدا شديد المهارة بطيعه الجنود ويأتمرون

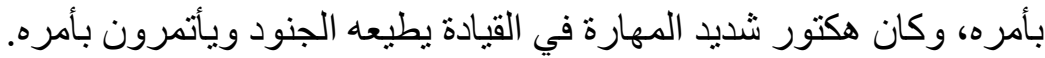

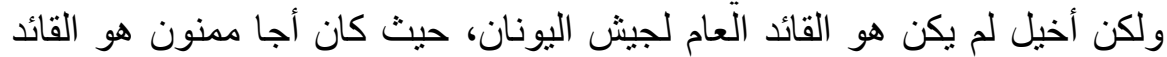

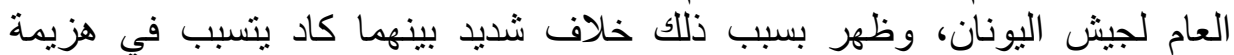

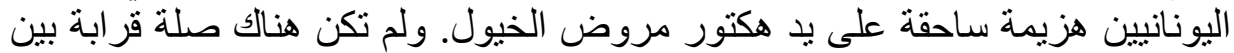

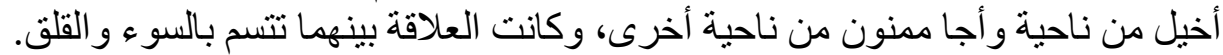

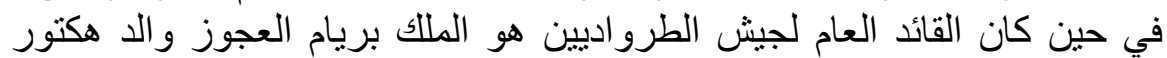

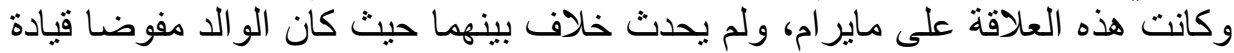

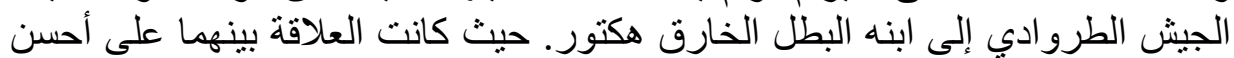

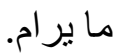

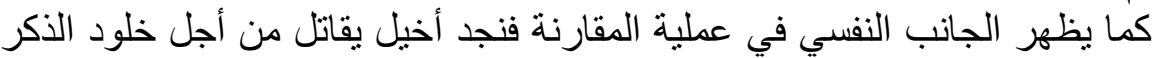

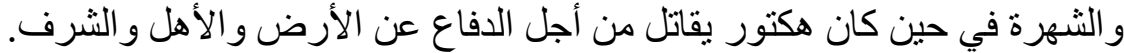

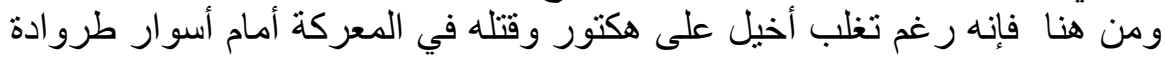

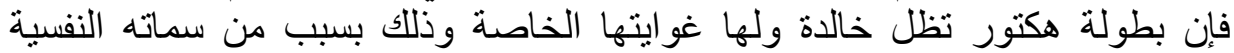

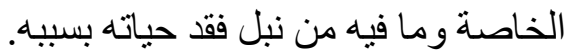
ويبدو من سمات هكتور النفسية حبه لزوجنه ونه وأسرته وأرضه ودفاعه بروحه عن كل ذلك.

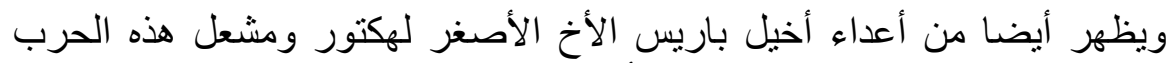

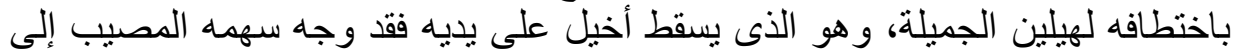

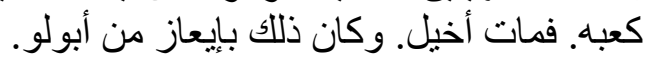

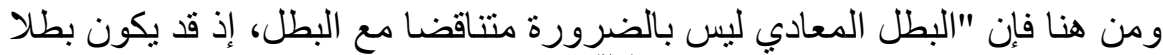

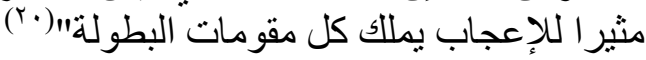

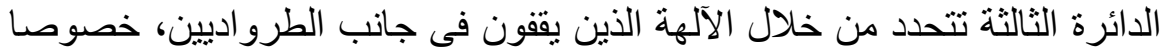

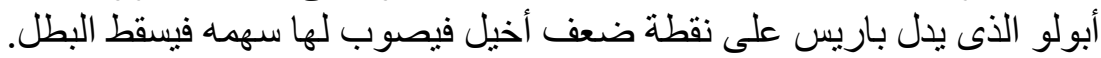

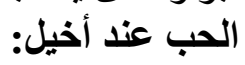
يظهر الحب عند بطل ملحمة الإلياذة من خلال قصة العلاقة الثهيرة مع الأسيرة

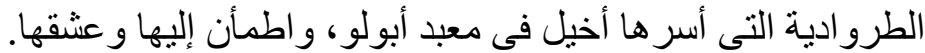

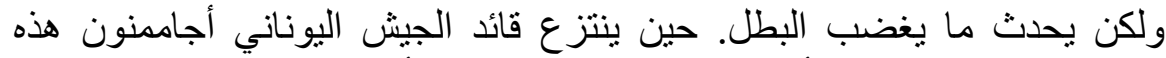

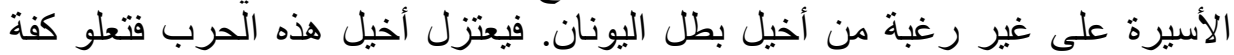

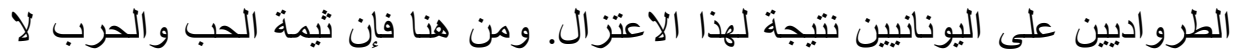


نعدمها فى الملحمة اليونانية. هذه الثيمة التي ظهرت ملامحها بصور مختلفة، فمنها حب النبا أخيل لأسيرته الطروادية برسيس، وعلاقة العشق والاختطاف بين باريس وهيلين التي كانت السبب

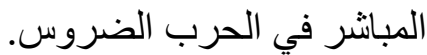
أما علاقة هكتور بزوجته أندروماك فلها مذاق خاص لأنها الحب العميق بين زوجين متفاهمين. فضاء الرحلة:

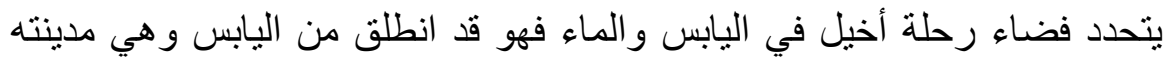

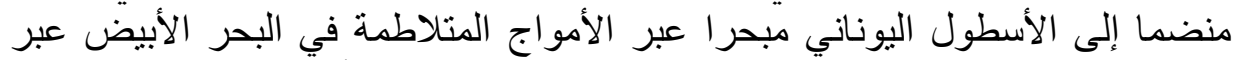

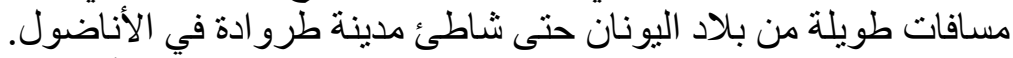

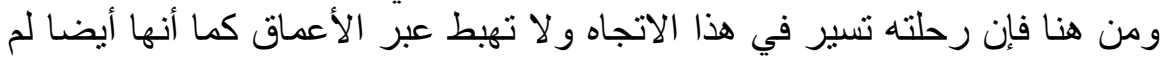

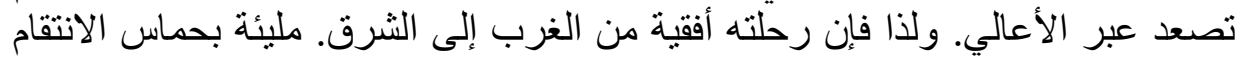

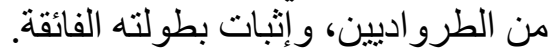

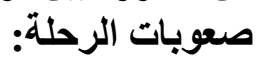

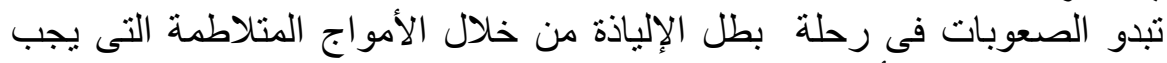

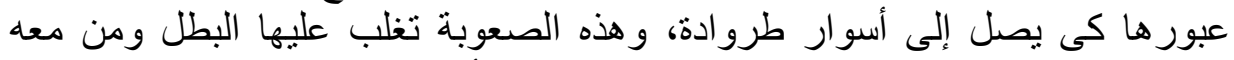

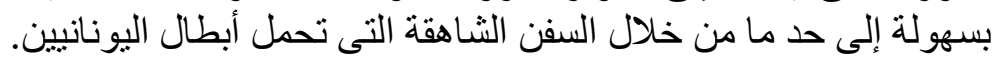

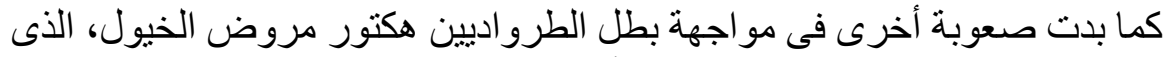

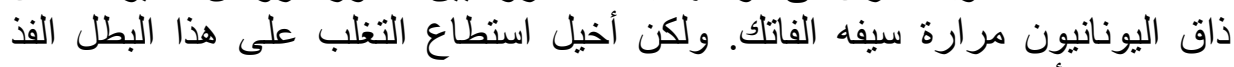
بمعاونة من أثنينا. وتتمثل الصعوبة الثالثة في جيش الطرواديين الجرار من أبطال يدافعون ببسالة عن وطنهم، لكن أخيل بذل فى ذلك ألك أوفى نصيب و وأذاقهم الأمرين.

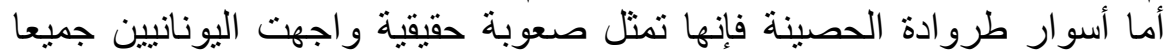

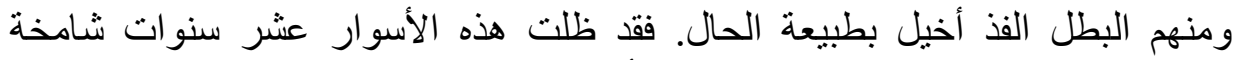

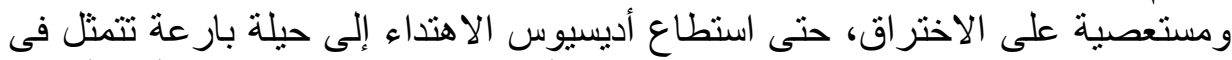

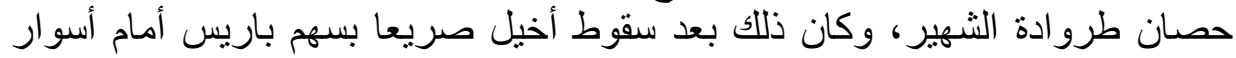
طرو ادة الثـامخة.

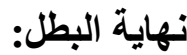

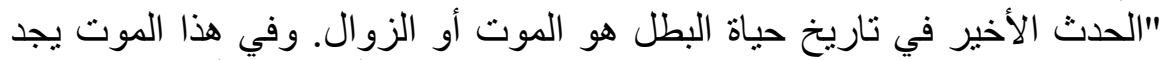

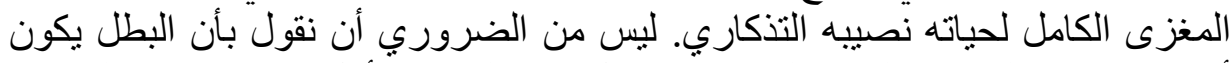

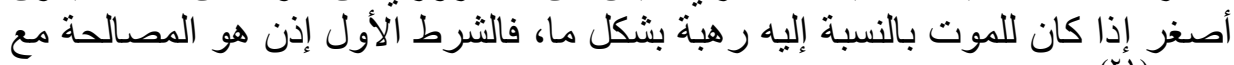

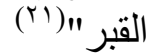


لم تتحقق للبطل العودة من رحلته شديدة الخطورة فقد مات على أرض طرو ادة ولم

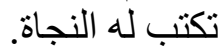

وقد كانت هذه النهاية تحقيقا لنبو عة قدمتها أم البطل أخيل له. وقد اختار السير فى

$$
\text { رحلته رغم معر فتته بمصيره فيها. }
$$

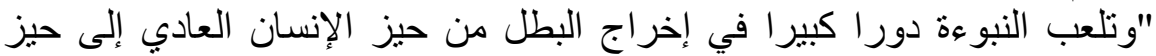

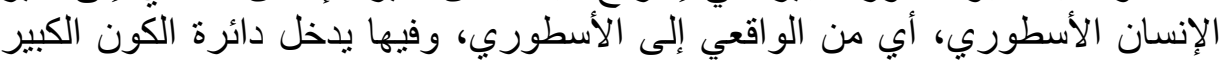

ليصبح مرتبطا به ارتباطا وثيقا.

والنبوءة هي الإخبار بالمستقبل قبل وقو عه، أي أنها قراءة الغيب وتعرف ما هو

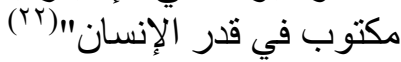

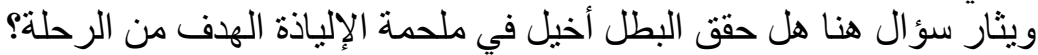

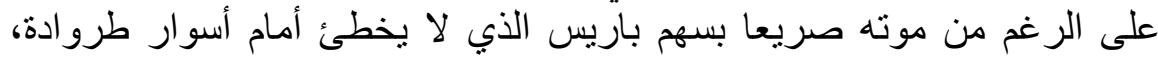

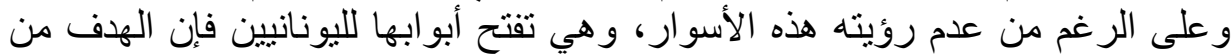

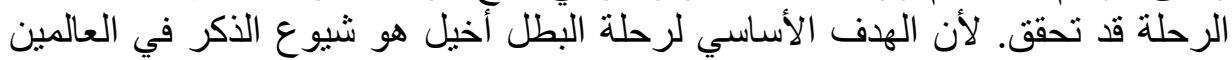

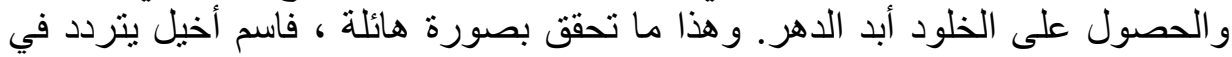
جنبات المعورة حتى الآن باعتباره البطل المفرد في هذه الحرب الطاحنة.

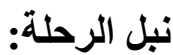

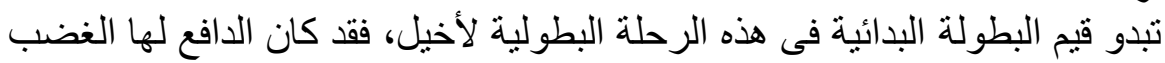

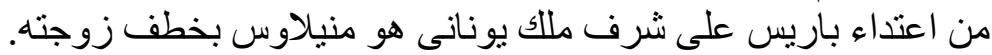

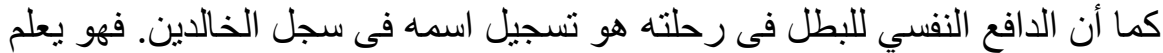
أن هذه الحرب من الضخامة بمكان، ويشترك فيها أبطال عظام فأراد أن بستوفى منها و هذه الغاية كانت شديدة النبل في الأزمنة القديمة، حيث كانت تمجد هذه الأزمنة قيم

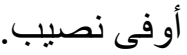

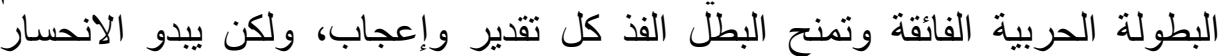

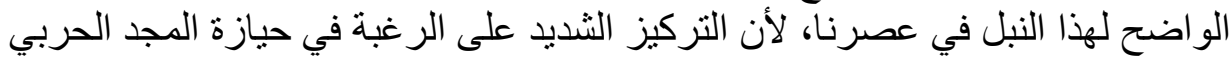

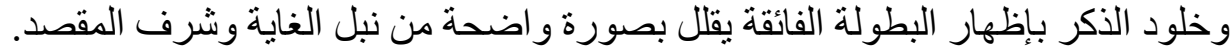

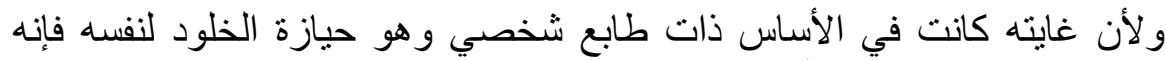

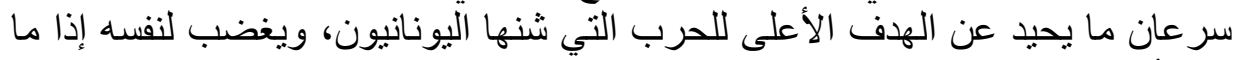

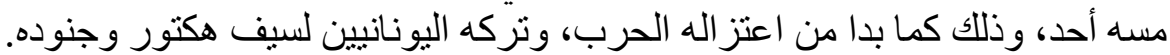
رحلة البطل من حيث الإجبار والاختيار: في رحلة أخيل مع الجنود اليونانيين عبر الأمو اج المتلاطمة كانت سمة الاختيار

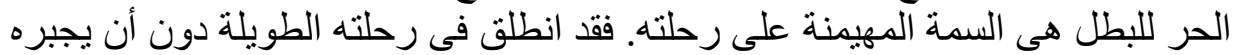
أحد عليها. و إنما تحرك بدافع من نفسه الر اغبة في خلود الذكر. 
وقد علمت أمه حورية البحر ثيتيس بأن ابنها سيلقى حتفه وهو في شرخ الثباب أمام

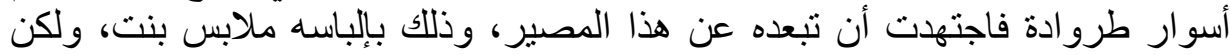

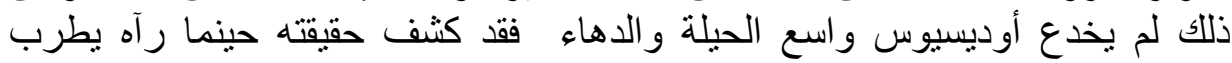
للسلاح. واستطاع إقناعه بالذهاب مع اليونانيين إلى الحرب الطئ الطرو ادية. خلود البطل:

يبدو خلود هذا البطل بصورة والبطا واضحة في الوجدان العالمي من خلال ما كتب عنه وما تناول حياته وما صنعه الخيال.

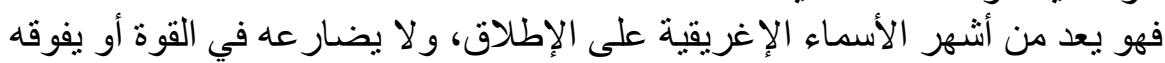
غير هيرقليس فائق القوة. هذا على العموم، اما على الفى الخصوص فهو أنشهر بطل على الإطلاق في حرب طرو ادة. وقراء إلياذة هوميروس الخالدة لا يحصون كثرة، وكان ذلك من أسباب شهرة هذا البطل في جنبات المعدورة. وقد ألهبت شخصيته الخيال، وجعلت السينما تتناولها في الكثير من أعمالها، ويعد

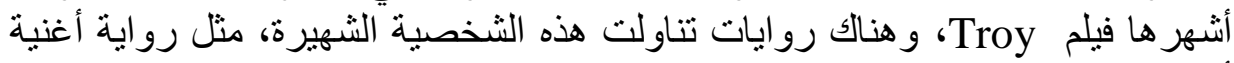
أما دارسو الأدب القديم والمتخصصون في الملاحم فلهم حضور هم الفذ في عالمنا

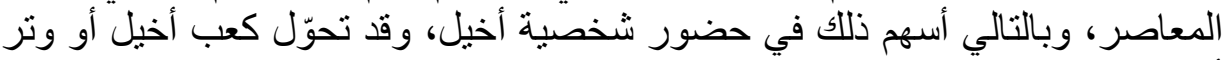

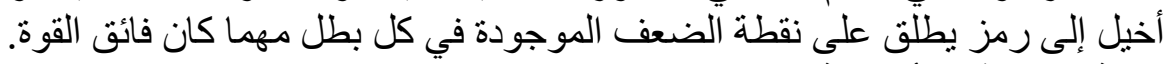
رحلة البطل فى الأوديسة: تتتاول أوديسة هو ميروس الاوديسة عودة البطل أوديسيوس من حرب طرو ادة هو ورجاله.

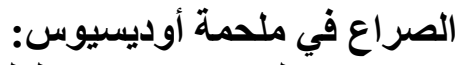

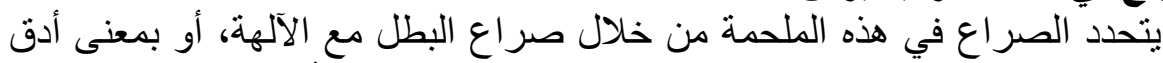

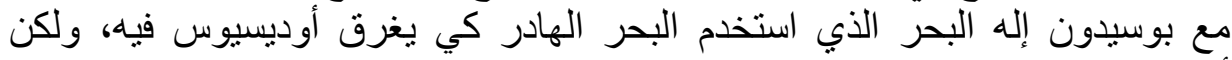
أوديسيوس استطاع التغلب على إله البحر البحر ، ونجا منه سالمًا.

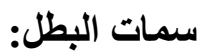
في هذه الملحمة نجد البطل بشرا خالصا، فهو ليس نصف إلهاء إلها، وإنما أبوه هو

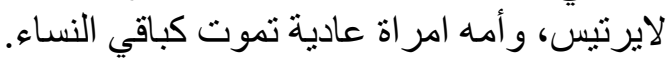

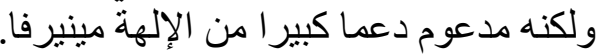

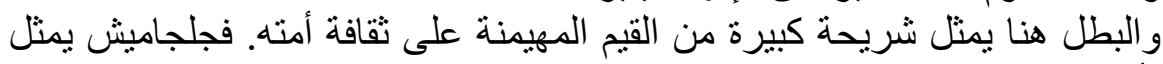

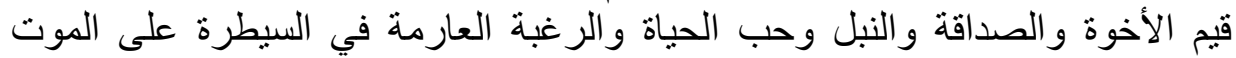
خاطف نفوس البشر. 


$$
\text { و أخيل يمثل قيم القوة الفائقة و الفروسية التي لا تعرف الكلل. }
$$

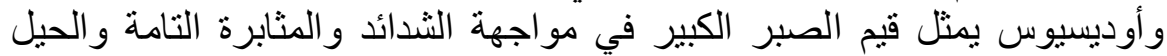

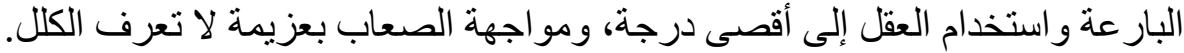

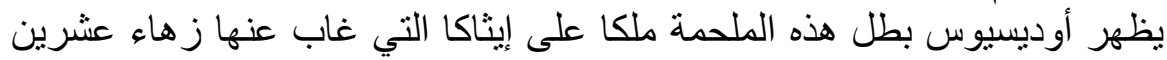

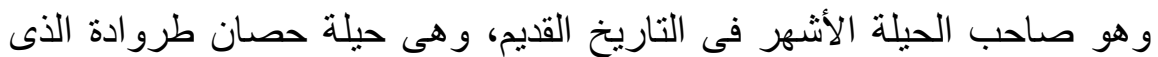

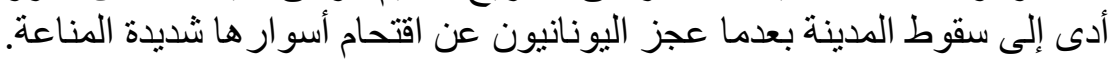

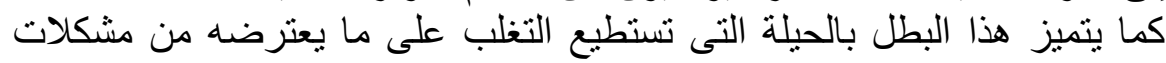

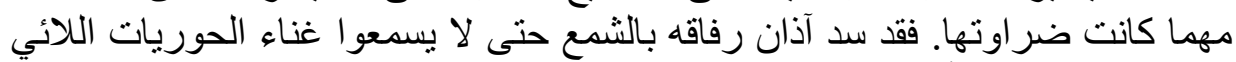

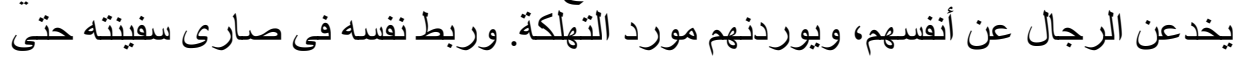

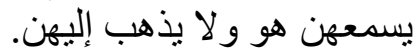
وتظهر قدرنه الفائقة على التهن التكيف مع أصعب الظروف. فقد اغترب عشرين عاما

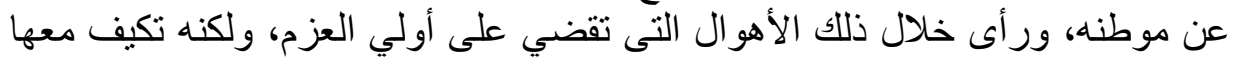

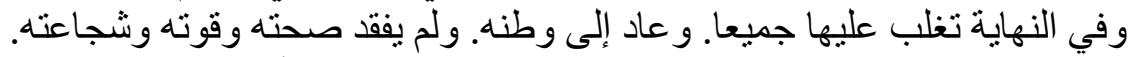

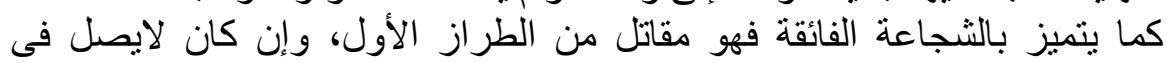

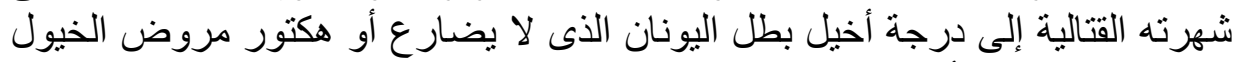

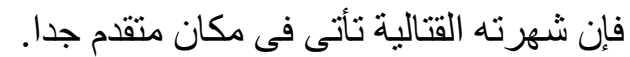

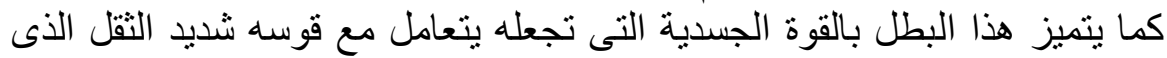

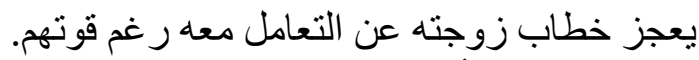

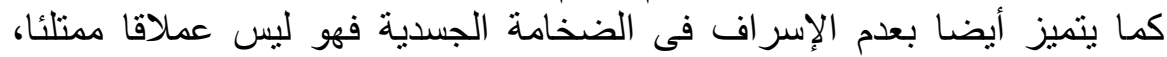

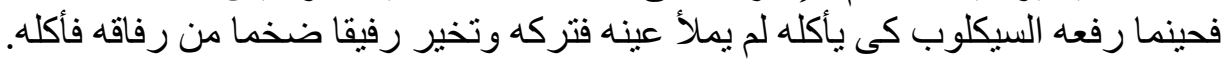

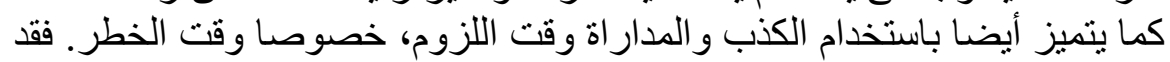

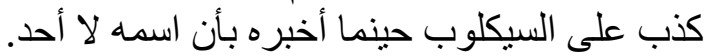

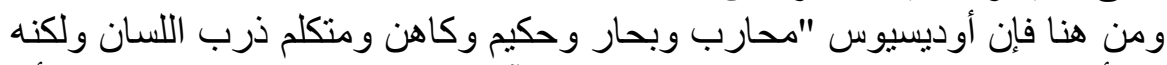

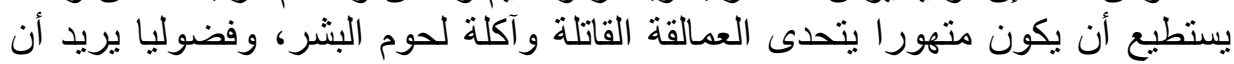

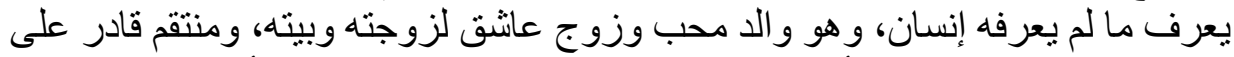

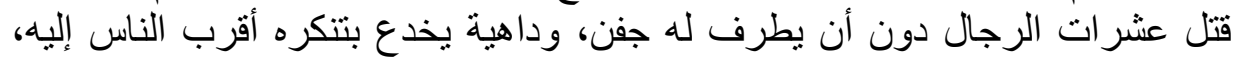

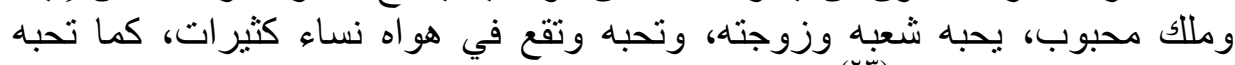

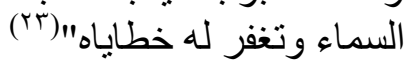
و البطل يعيش حتى نهاية عمره في هدوء ونه وسعادة وقناعة بما آل إليه أمره. ويموت في وطنه بين أسرته ور عيته فئه. ولكنه ييدو في مرحلة عمرية متقدمة هي عمر الكهولة، حيث كانت الإشارات 


$$
\text { الهـكررة إلى تقدمه في العمر عبر مقاطع الأوديسة. }
$$

يتحدد الهدف الأساسي من رحلة أوديسيوس فى العودة إلى اللى موطنه إيثاكا بعد الانتهاء من حرب طرو ادة الثهيرة. حيث زوجنه بنه بنيلوب و و وابنه تليماك ومملكتها.

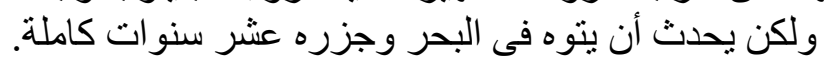

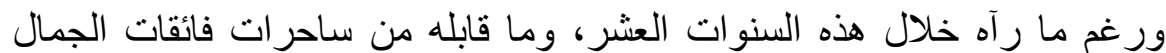

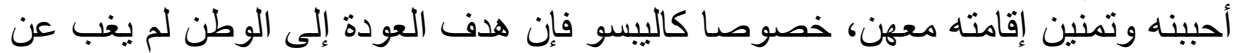
باله أبدا.

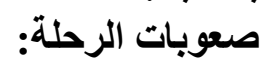

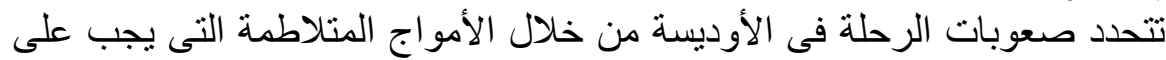

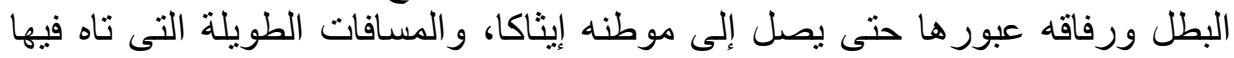

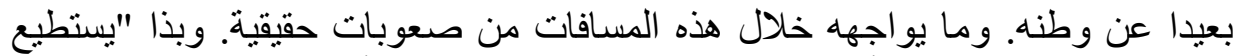

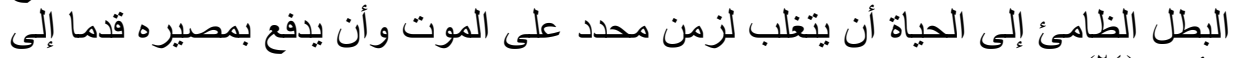

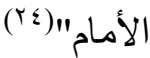
وقد ظهر للبطل أعداء كان كل همهم تعطيل مسيرة البطل أطول فترة ممكنة بل و القضاء عليه. ويعد بوسيدون أو نيبتون إله البحر هو أظهر هؤلاء الأعداء وأكثرهم أذى للبطل

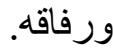
وقد اكتسب أوديسيوس عداوة إله البحر لما فعله مع السيكلوب لأنه كان ابنه. فقد

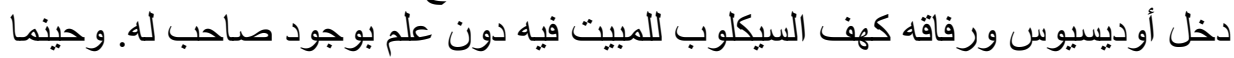

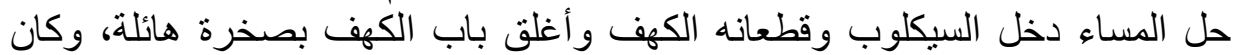
عملاقا هائلا بعين و احدة.

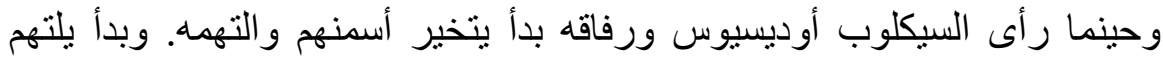

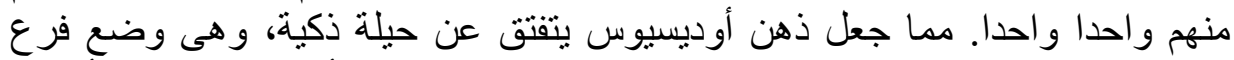

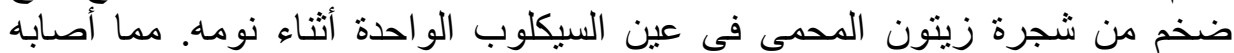

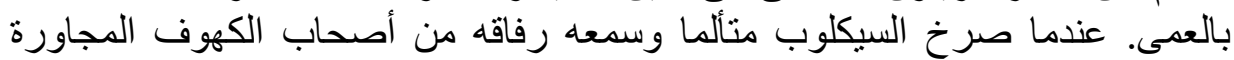

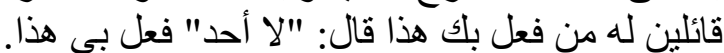
وكان هذا الاسم "لا أحد" هو الاسم الذئ اختى هذاره أوديسيوس لنفسه حينما سأله

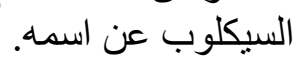

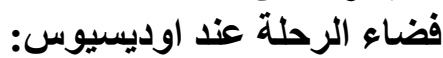

يتحرك البطل في رحلة الرديونة عودته تحركا أفقبا عبر البحر وأمواجه المتلاطمة ويتتل

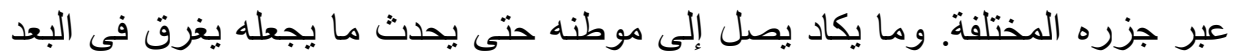


عنه. وقد كانت الرحلة من أقصى شرق المتوسط إلى أقصى غربه، ولم تكن الرحلة خطية، و إنما يقترب و ويتنعد و هكذا.

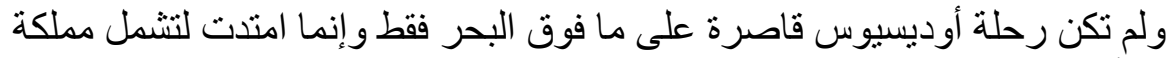

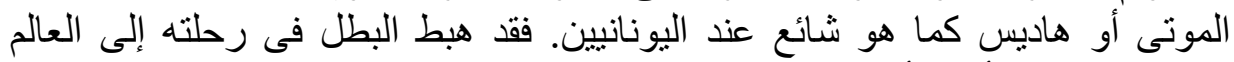

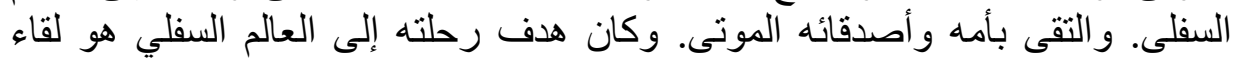

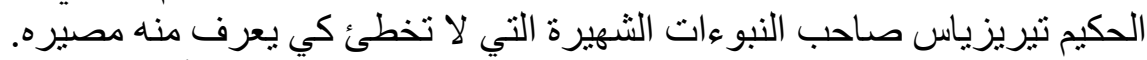

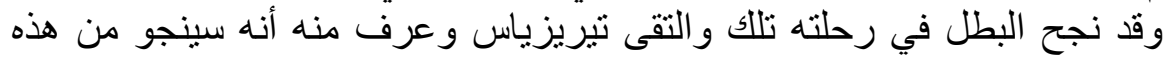

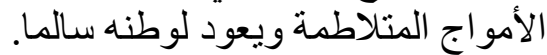

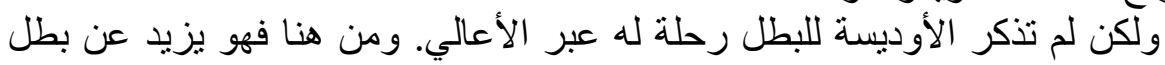

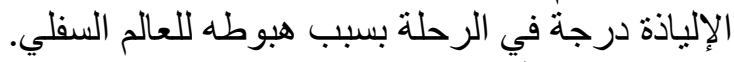

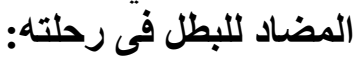

يتحدد المضاد هنا للبطل فى ثلاث دو ائر : الدائرة الأولى من على عالم ما فوق الطبيعة

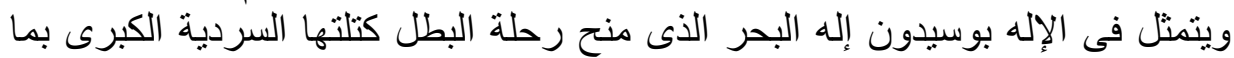

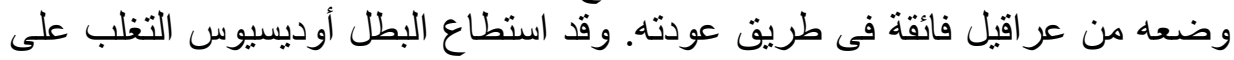

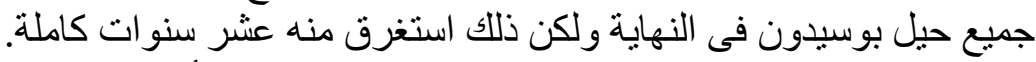

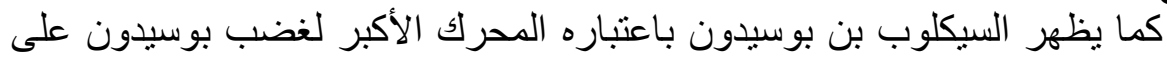

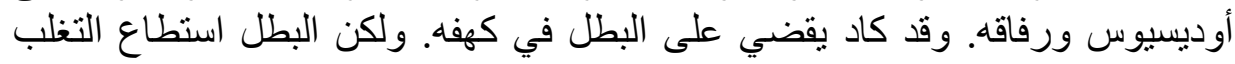
عليه بفقء عينه الو احدة.

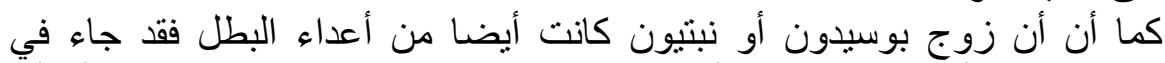

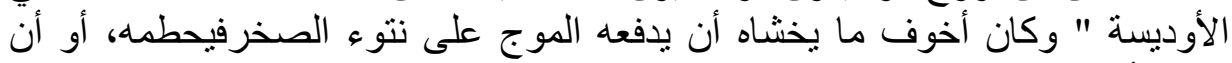

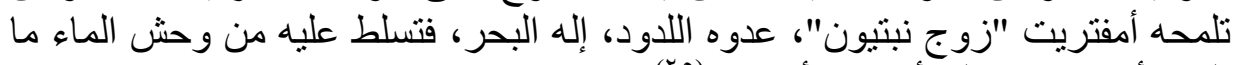

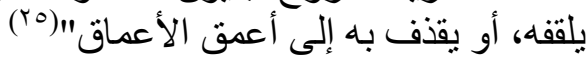

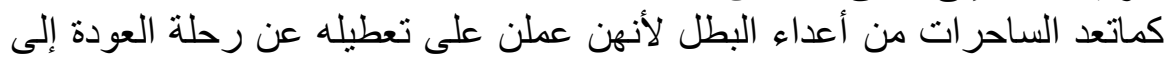

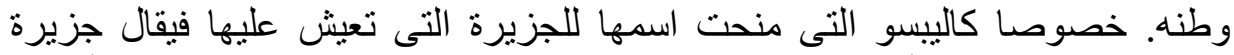

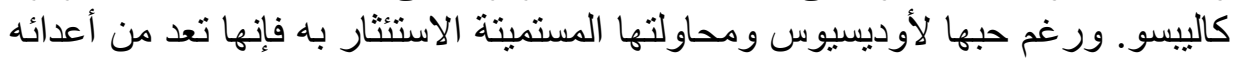

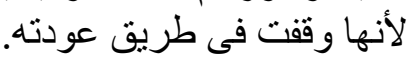
كما ظهر من أعدائه الهولة شديدة القبح و الدمامة ذات الرؤوس الست التهات التي أكلت في

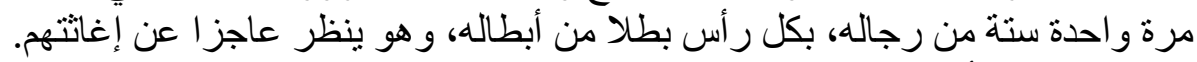

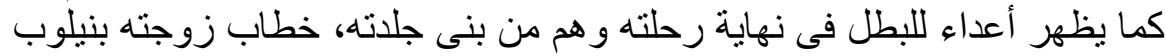

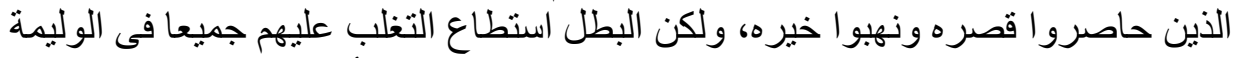

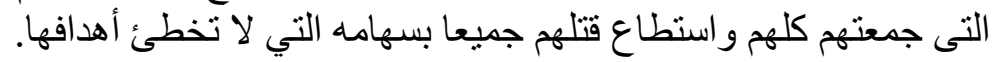


تبدو الإلهة مينرفا إلهة الحكمة هى أهم معين للبطل كي يتجاوز أزماته.

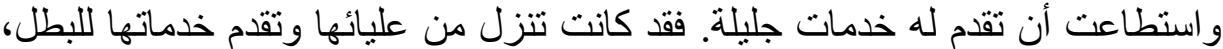

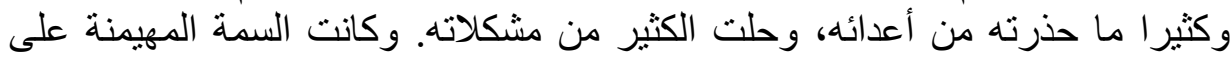

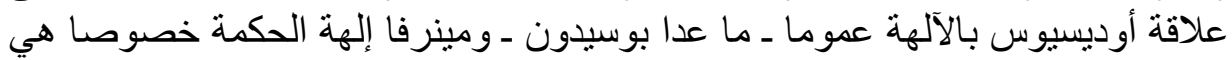

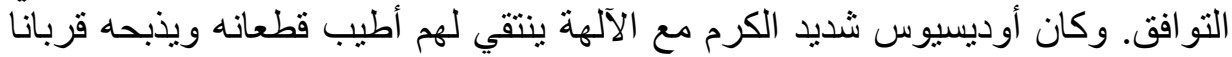

كما أن ملك شيريا وزوجته و ابنه و ابنته قدما للبطل خدمة جليلة، فقد تم استقباله في

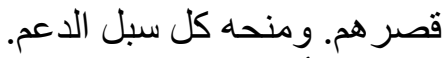

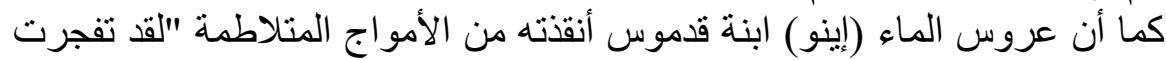

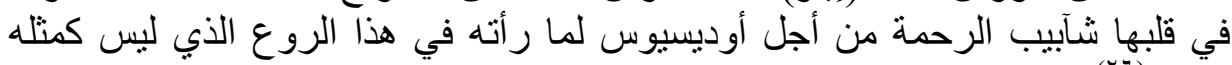

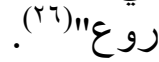
ثم قالت له: " ويحك أيها البائس فم أثرت غضبة نبتيون عليك حتى ليتبعك سربا في

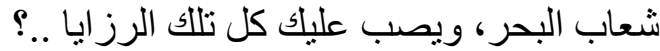

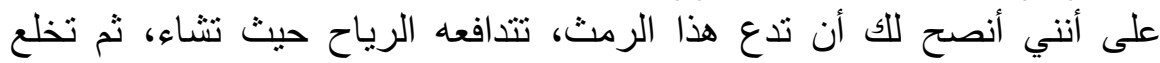

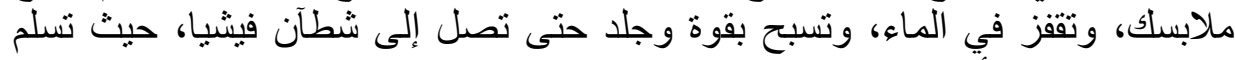

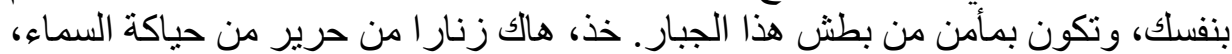

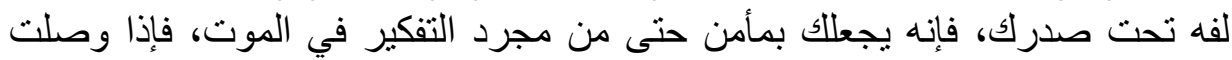

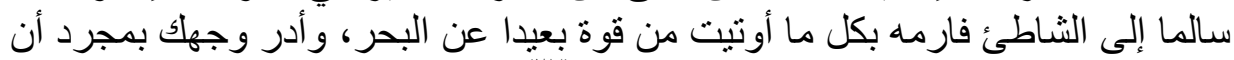

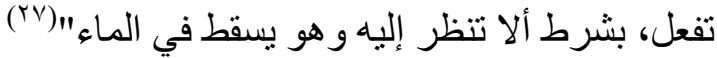

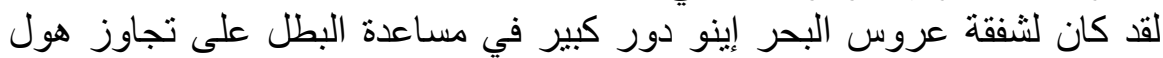
الأمو اج المتلاطمة، و الرياح العنة العنية.

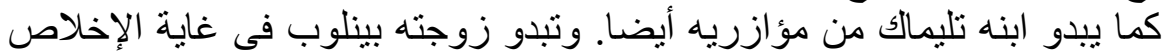

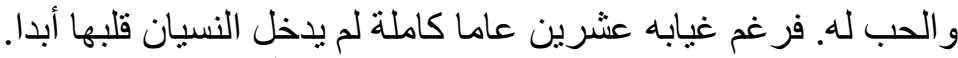

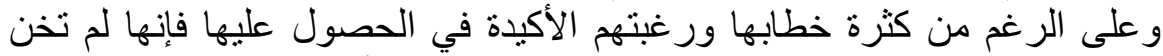

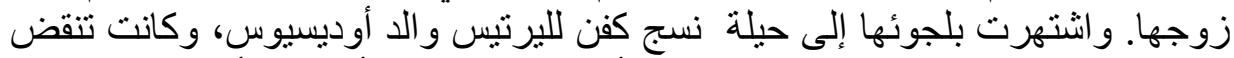

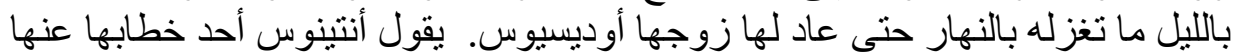

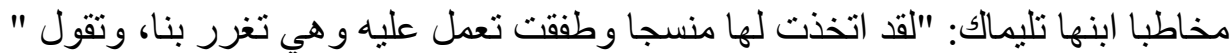

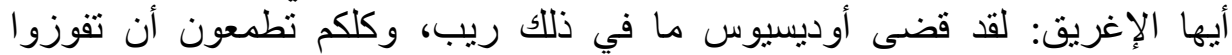

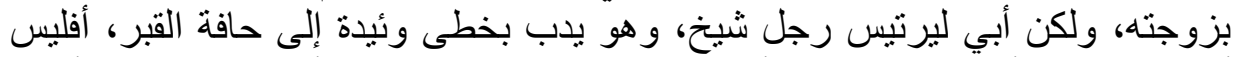

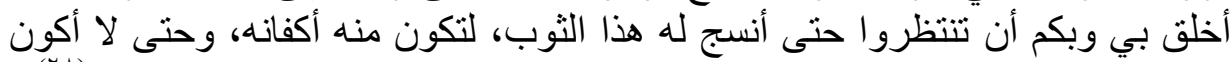

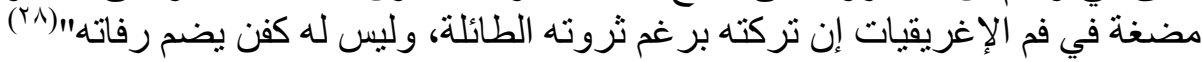


تتميز رحلة أوديسيوس بالنبل، لأنها رحلة عودة إلى أرض الوطنه الوطن، إلى زوجنه

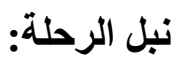

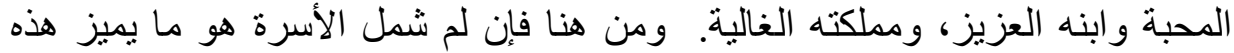
الرحلة من حيث النجاح و الفشل:

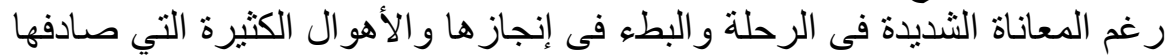

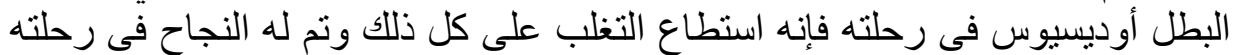

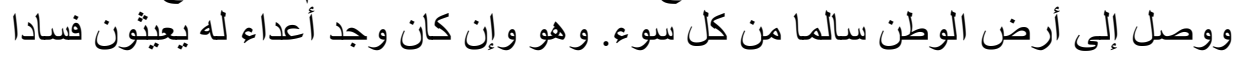

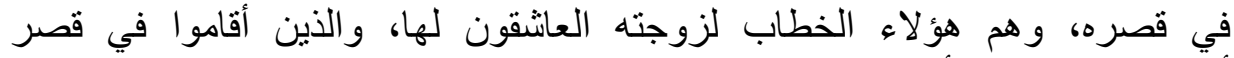

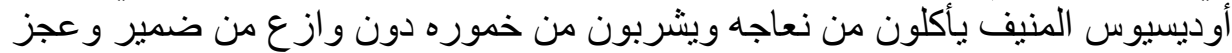

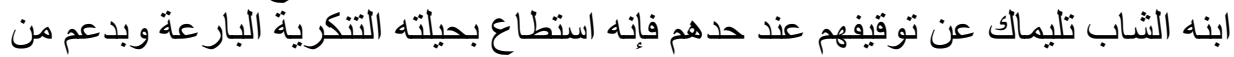
منيرفا إلهة الحكمة القضاء عليه توفي جميعا. 
كارل غ يونج، الإنسان ورموزه، سيكولوجيا العقل الباطن، ترجمة عبد الكان الكريم

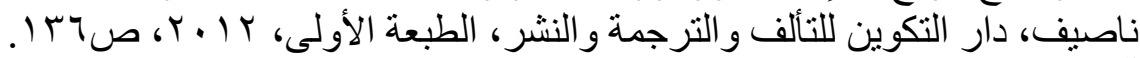

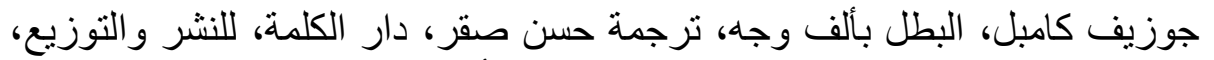

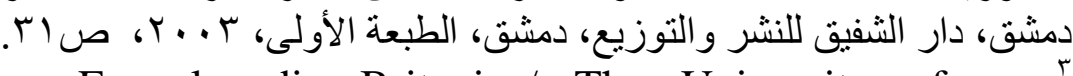
The New Encyclopedia Britanica/ The University of

ChicagoPress, USA, 15th edition, 1980, volume,v, p: 02 شكري محمد عياد، البطل في الأدب والأساطير، دار المعارف، القاهرة، مصر،

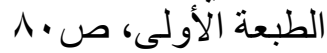
• نسيمة زمالي، البطل في الآداب العالمية: من الأسطورة إلى الحداثة، مجلة الذاكرة،

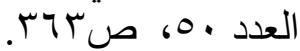
" هامش رقم ه من كاتب فن الثعر لأرسطو فن الشعر، ترجمة وتقديم وتعليق إبراهيم

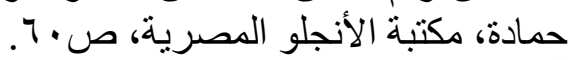

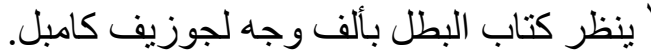

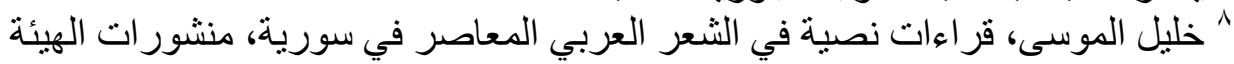

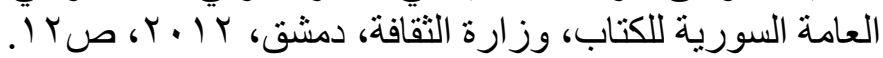

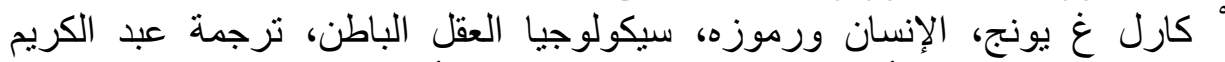

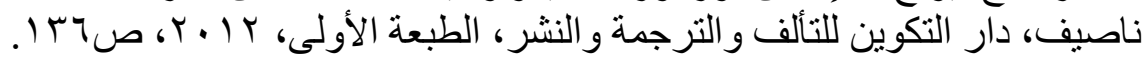

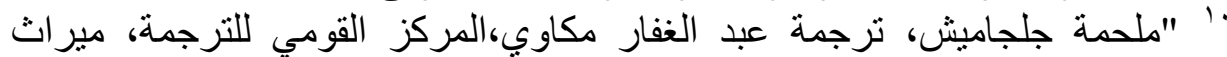

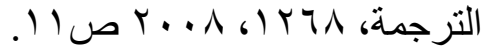

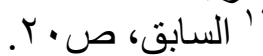

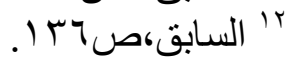

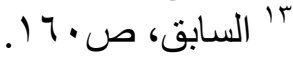

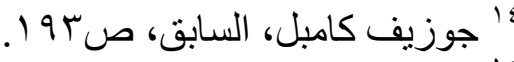

$$
\begin{aligned}
& \text { 10 } 10 \\
& \text { 17 } 19
\end{aligned}
$$

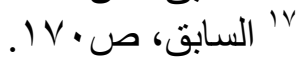

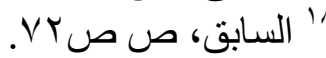

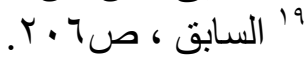

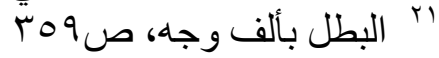

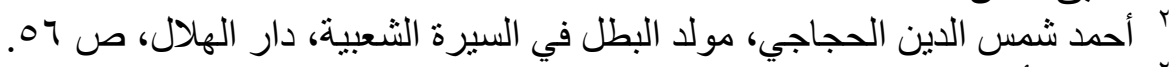




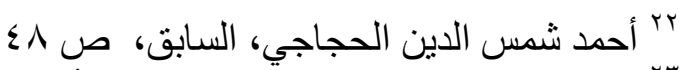

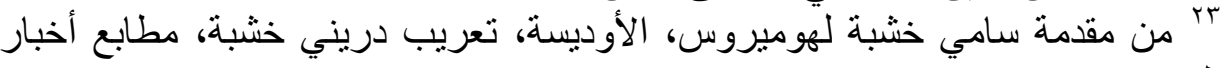

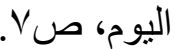

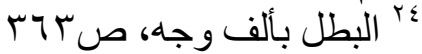

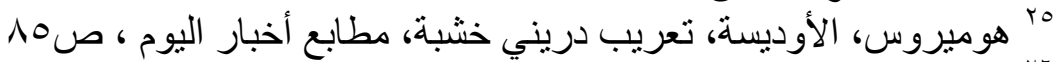
Tr الأوديسة، صبروس، صYم الأديسة

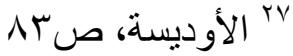

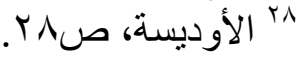


